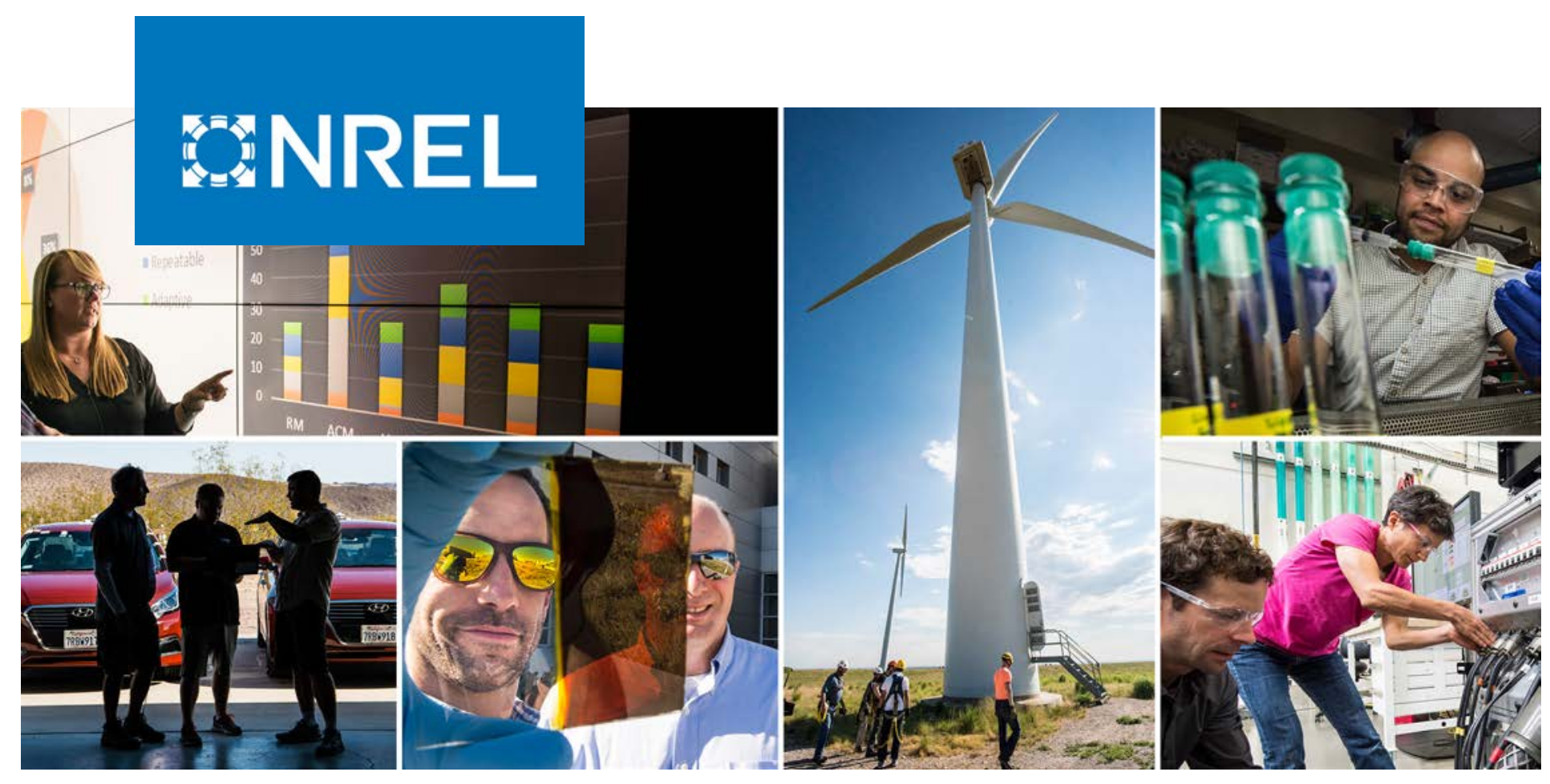

\title{
Evaluation of High Rotor Pole Switched Reluctance Motors to Control Condenser Fans in a Commercial Refrigeration System
}

Grant Wheeler and Michael Deru

National Renewable Energy Laboratory

NREL is a national laboratory of the U.S. Department of Energy Office of Energy Efficiency \& Renewable Energy

Operated by the Alliance for Sustainable Energy, LLC

This report is available at no cost from the National Renewable Energy Laboratory (NREL) at www.nrel.gov/publications.

\section{Technical Report}

NREL/TP-5500-72476

June 2019 


\title{
GHREL
}

\section{Evaluation of High Rotor Pole Switched Reluctance Motors to Control Condenser Fans in a Commercial Refrigeration System}

\author{
Grant Wheeler and Michael Deru
}

National Renewable Energy Laboratory

\section{Suggested Citation}

Wheeler, Grant, and Michael Deru. 2019. Evaluation of High Rotor Pole Switched Reluctance Motors to Control Condenser Fans in a Commercial Refrigeration System. Golden, CO: National Renewable Energy Laboratory. NREL/TP-5500-72476.

https://www.nrel.gov/docs/fy19osti/72476.pdf.

NREL is a national laboratory of the U.S. Department of Energy Office of Energy Efficiency \& Renewable Energy Operated by the Alliance for Sustainable Energy, LLC

This report is available at no cost from the National Renewable Energy Laboratory (NREL) at www.nrel.gov/publications.

Contract No. DE-AC36-08GO28308
Technical Report NREL/TP-5500-72476 June 2019

National Renewable Energy Laboratory 15013 Denver West Parkway Golden, CO 80401

303-275-3000 • www.nrel.gov 


\section{NOTICE}

This work was authored by the National Renewable Energy Laboratory, operated by Alliance for Sustainable Energy, LLC, for the U.S. Department of Energy (DOE) under Contract No. DE-AC36-08G028308. Funding provided by the U.S. Department of Energy Office of Energy Efficiency and Renewable Energy Building Technologies Office. The views expressed herein do not necessarily represent the views of the DOE or the U.S. Government.

This report is available at no cost from the National Renewable Energy Laboratory (NREL) at www.nrel.gov/publications.

U.S. Department of Energy (DOE) reports produced after 1991 and a growing number of pre-1991 documents are available free via www.OSTI.gov.

Cover Photos by Dennis Schroeder: (clockwise, left to right) NREL 51934, NREL 45897, NREL 42160, NREL 45891, NREL 48097, NREL 46526.

NREL prints on paper that contains recycled content. 


\section{Acknowledgments}

The authors would like to thank Walmart Inc. for donating the facility and the time to complete the motor installation and work on-site. We'd also like to thank VaCom Technologies for fixing sensor issues at the beginning of the project and for counseling the authors during the project.

Finally, we appreciate the funding from the U.S. Department of Energy's High Impact Technology Catalyst program to complete this work.

The U.S. Department of Energy's High Impact Technology Catalyst program enables federal and commercial building owners and operators to make sound investment decisions in nextgeneration building technologies based on their real-world performance.

For more information, contact:

Grant Wheeler

National Renewable Energy Laboratory

Email: grant.wheeler@nrel.gov 


\section{List of Acronyms}

$\operatorname{Cin}_{T 2}$

$\mathrm{Cin}_{\text {T2,Diff }}$

CFS

CFSC

Cond $_{T D}$

Dis $S_{P r}$

EEM

EIA

FPR

FNR

HRSR

HRSRM

HVAC

$\mathrm{Hz}$

$\mathrm{kW}$

$\mathrm{kWh}$

NIST

NMBE

NREL

$O A_{T}$

psi

RMSE

rpm

RTD

SMC

SV

$\mathrm{T}$

VFD

VHP

VHPC condenser inlet temperature Circuit 2

difference of condenser inlet temperature Circuit 2

constant fan speed

constant fan speed control

legacy condenser temperature difference

discharge pressure

energy-efficiency measure

U.S. Energy Information Administration

false positive ratio

false negative ratio

high rotor pole switched reluctance

high rotor pole switched reluctance motor

heating, ventilating, and air conditioning

hertz

kilowatt

kilowatt-hour

National Institute of Standards and Technology

normalized mean bias error

National Renewable Energy Laboratory

outdoor air temperature

pounds per square inch

root mean square error

revolutions per minute

resistance temperature detector

Software Motor Company

split valve

temperature $\left({ }^{\circ} \mathrm{F}\right)$

variable frequency drive

variable head pressure

variable head pressure control 


\section{Executive Summary}

The goal of this project was to evaluate a high rotor pole switched reluctance (HRSR) motor system for use as a condenser fan motor for commercial refrigeration systems. The HRSR motor is purportedly more efficient than induction motors for all motor speeds and is inherently variable speed. Two baselines were developed with the legacy induction motor that represent common motor control using constant fan speed (CFS) control or variable head pressure (VHP) control, which dynamically adjusts the condenser motor speed based on the outdoor air temperature and discharge compressor pressure. Four energy-efficiency measures (EEMs) were evaluated as different combinations of control strategy and motor, as described in Table 1.

Table 1. Description of the Four Scenarios That Were Evaluated

\begin{tabular}{lllll}
\hline Scenario & Baseline Control & EEM Control & Baseline Motor & EEM Motor \\
\hline 1 & CFS & CFS & Induction & HRSR \\
2 & VHP & VHP & Induction & HRSR \\
3 & CFS & VHP & Induction & Induction \\
4 & CFS & VHP & Induction & HRSR \\
\hline
\end{tabular}

* The field demonstration was configured to run VHP control for both induction and HRSR motors. However, because of differences in induction and HRSR motor speeds during the demonstration, the only measured values used were for the baseline with VHP control.

Nine 1.5 horsepower HRSR motors were installed parallel to the same number of legacy induction motors with VHP control for a commercial supermarket refrigeration system in Lakeside, Colorado.

Determination of the relationship between condenser power and motor speed was performed over a 2-month period. Annual data that had been collected for 2017 were then leveraged to predict the annual energy savings for the four scenarios described in Table 1. Table 2 displays the quantitative results.

Table 2. Quantitative Performance Results

\begin{tabular}{lllll}
\hline Scenario & $\begin{array}{l}\text { Baseline Energy } \\
\text { (kWh/motor) }\end{array}$ & $\begin{array}{l}\text { EEM Energy } \\
\mathbf{( k W h / m o t o r )}\end{array}$ & $\begin{array}{l}\text { Savings } \\
\text { (kWh/motor) }\end{array}$ & $\begin{array}{l}\text { Savings } \\
\text { (\%) }\end{array}$ \\
\hline 1 & 6,186 & 4,369 & 1,817 & $29 \%$ \\
2 & 2,641 & 1,775 & 866 & $33 \%$ \\
3 & 6,186 & 2,641 & 3,545 & $57 \%$ \\
4 & 6,186 & 1,775 & 4,411 & $71 \%$ \\
\hline
\end{tabular}

Note: $\mathrm{kWh}=$ kilowatt-hour

Results from Table 2 show that the HRSR motor was more efficient than the legacy induction motors regardless of the type of condenser control. The 4\% increase in percent energy savings between Scenario 1 and Scenario 2 is likely because of the improved performance of the HRSR motor at low motor speeds. This is further detailed in the report by comparing power savings as a 
function of motor speed. Although the HRSR motor saved 29\% power at 870 revolutions per minute, the power savings increased to $58 \%$ at 200 revolutions per minute.

Further, 57\% energy savings was found by implementing VHP control, indicating that VHP control alone can significantly reduce condenser energy consumption. The most energy savings was found when implementing both VHP control and HRSR motors as shown in Scenario 4, resulting in $71 \%$ savings.

This report only looked at the condenser energy savings. However, when considering an entire refrigerant system including compressors, energy savings for Scenario 3 and Scenario 4 would be less. This is because reduced airflow across the condenser (as a result of reduced motor speed) would increase the refrigerant discharge pressure and the compressor power consumption. While changes in compressor energy were not measured, estimates of the increased compressor energy show that it is small compared to the condenser fan energy savings.

Additional considerations for the HRSR motors were also noted during the project. First, the HRSR motor system includes real-time operational monitoring for speed, torque, and power and made it possible to identify and remotely shut down an individual motor when a piece of foam locked the fan and thereby the motor. With the traditional system, a locked rotor could have caused motor damage unless a breaker or fuse were activated. The EEM's additional sensing capability could enhance the fault detection and diagnostics capability of refrigeration automation systems.

For the second consideration, as a result of resonant frequency issues, the HRSR motor's rampup time was increased to a minute. After implementing this change, no issues for excessive vibration were recorded. 


\section{Table of Contents}

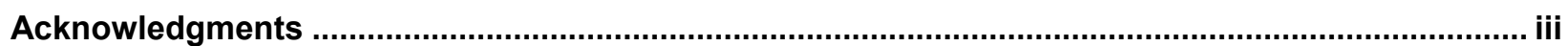

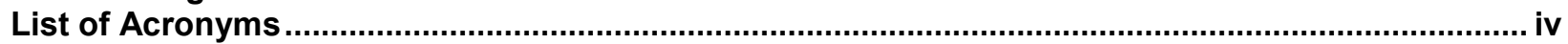

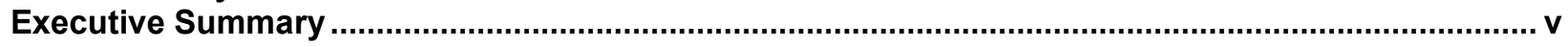

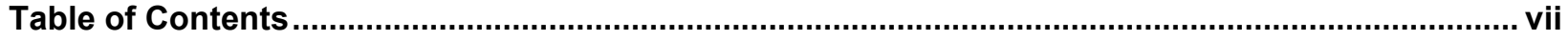

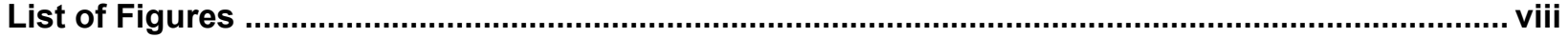

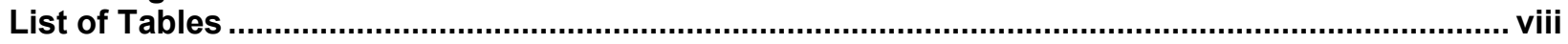

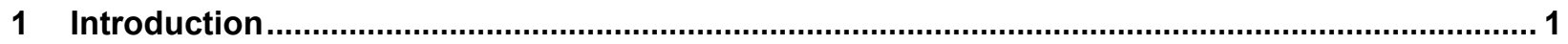

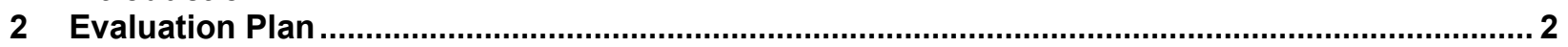

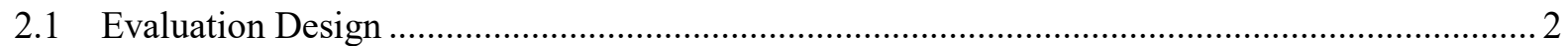

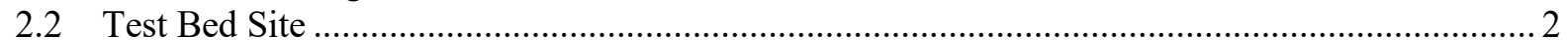

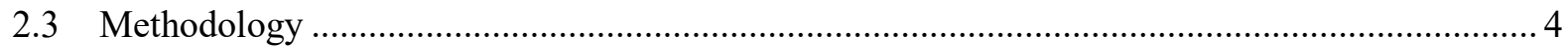

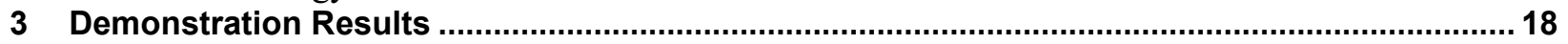

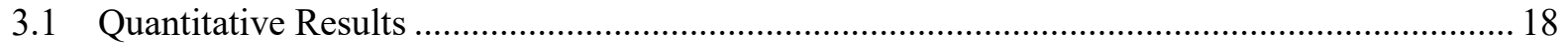

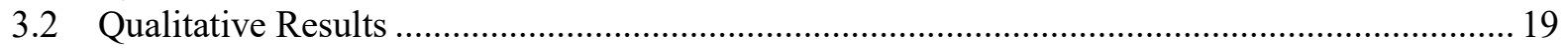

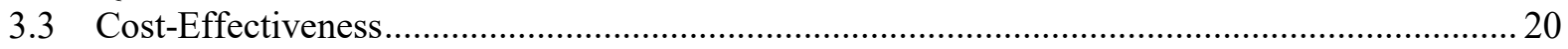

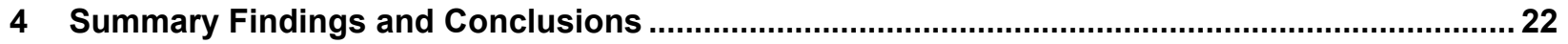

4.1 Overall Technology Assessment at Demonstration Facility ................................................... 22

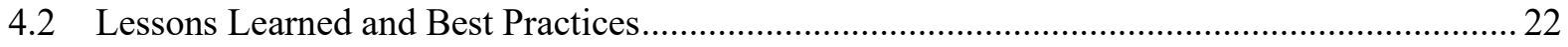

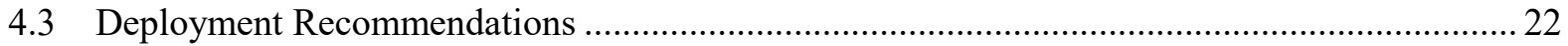

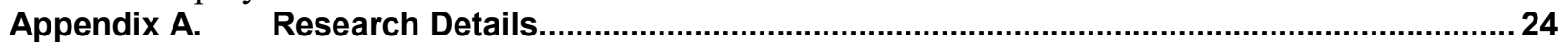

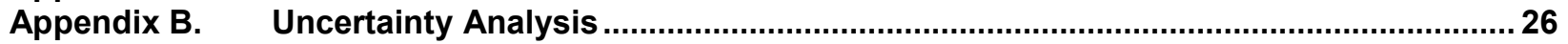

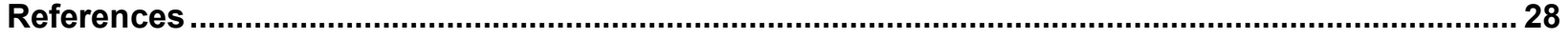




\section{List of Figures}

Figure 1. Illustration of the installation of the HRSR motors for a supermarket condenser........................ 3

Figure 2. Condenser rack configuration after installation of the HRSR motors ...................................... 4

Figure 3. Steady-state data set comparison of HRSR and legacy motor speeds for (left) Rack A and (right) Rack B...

Figure 4. Illustration of the three-step process for predicting the HRSR motor power to validate the power models for the validation data set only ........................................................................... 10

Figure 5. Range of NMBE values for HRSR motor power as a function of the exponent for (left) Rack A

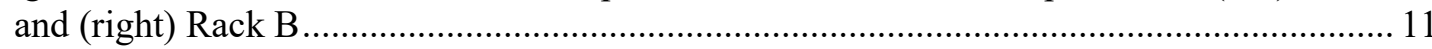

Figure 6. Range of NMBE values for the HRSR motor power as a function of the exponent for the legacy

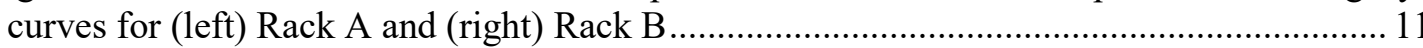

Figure 7. Difference in power between HRSR and legacy motors as a function of motor speed............... 12

Figure 8. Illustration comparing the three-step process to calculate HRSR motor power for (left) the validation data set and (right) the annual data set ............................................................. 13

Figure 9. Condenser power versus outdoor air temperature using VHP control for (left) Rack A and (right) Rack B (Note: VHPC = variable head pressure control.) .......................................... 14

Figure 10. Condenser power versus outdoor air temperature using CFS control for (left) Rack $A$ and (right) Rack B (Note: CFSC = constant fan speed control.) ............................................... 15

Figure 11. Parity plot between site and Weather Underground station outdoor air temperature................ 16

Figure 12. Foam jamming the condenser fan with an HRSR motor installed ......................................... 20

\section{List of Tables}

Table 1. Description of the Four Scenarios That Were Evaluated......................................................... v

Table 2. Quantitative Performance Results............................................................................................

Table 3. Baseline and Energy-Efficiency Measures Evaluated for Annual Energy Savings....................... 2

Table 4. Qualitative Performance Objectives ....................................................................................... 2

Table 5. Coordination and Responsibilities by Organization ............................................................... 4

Table 6. Monitoring and Instrumentation for a Walmart Refrigeration System in Store 5957 ................... 5

Table 7. Description of Different Test Periods .................................................................................... 5

Table 8. Low Ambient Temperature Control Models and Their Accuracy ............................................... 9

Table 9. Chosen Parameters for Power Curves Describing Legacy and High Rotor Pole Switched Reluctance Motor Relationships to Speed ....................................................................... 12

Table 10. Temperature Ranges and Power Patterns for Extremely Low Ambient Temperature Control... 14

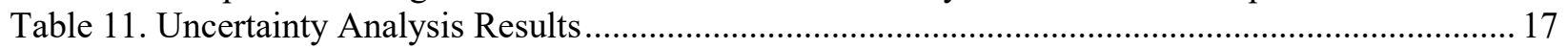

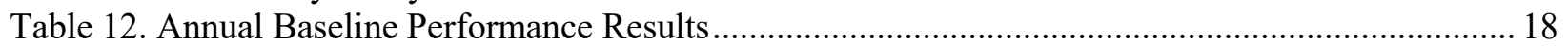

Table 13. Energy Savings for Rack A and Rack B .............................................................................. 19

Table 14. Average Monthly Peak Power Reduction Based on 15-Minute Intervals for All Four Scenarios

Table 15. Annual and 3-Year Simple Savings Analysis per Motor for a Complete Replacement .............. 21

Table 16. Curve Fits for Legacy and High Rotor Pole Switched Reluctance Motor Power Consumption

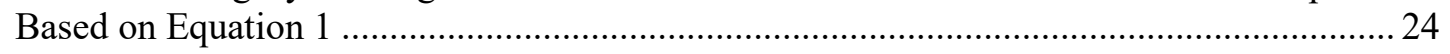

Table 17. Description of Prefilters for the Steady-State Data Set...................................................... 24

Table 18. Additional Details of Low Ambient Temperature Control Models ......................................... 25

Table 19. Variables for Determining the Uncertainty of the Annual Energy Savings.............................. 26

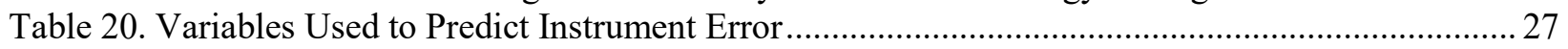

Table 21. Motor Speed Measurement Error................................................................................... 27 


\section{Introduction}

The goal of this project was to evaluate a high rotor pole switched reluctance (HRSR) motor system for use as a condenser fan motor for commercial refrigeration systems. At 1-10 horsepower (hp), the HRSR motor is sized appropriately for most commercial refrigeration condenser fan motors. Switched reluctance motors have high efficiencies with no rare-earth materials but have historically had control, noise, and vibration challenges that prevented them from being used for most building applications. The HRSR motor design and control system has overcome these challenges, is more efficient than induction and electronically commutating motors, and is inherently variable speed.

A Walmart Supercenter in Lakeside, Colorado, was used for the field demonstration site. This site has a double rack, low- and medium-temperature commercial refrigeration system with 18 condenser fan motors. The 1.5-horsepower legacy induction motors driving the condenser fans have nameplate efficiencies of $73.5 \%$, while the HRSR motors have nameplate efficiencies of $93 \%$ and maintain high motor efficiencies even at low motor speeds. Given these efficiency ratings, the team's hypothesis was that the HRSR motors would outperform the induction motors for both constant fan speed and variable fan speed operation.

There are two common types of control for commercial refrigeration condenser fans. The most basic control is known as constant fan speed (CFS) control, which never modulates fan speed. Variable head pressure (VHP) control modulates the condenser fan speed to maintain a temperature difference between the outdoor air temperature $\left(O A_{T}\right)$ and the saturated condenser temperature. This type of control is meant to optimize heat dissipation from the condenser while reducing the net refrigerant power consumption. Both control strategies are also commonly combined with some type of low ambient temperature control, ensuring stable evaporator performance by maintaining a high condenser pressure, even when - under normal operationthe condenser pressure would lower proportionally with ambient temperature. For CFS control, where the condenser fans cannot modulate, a common method is to cycle the motors on and off. For VHP control, the fan speed can be reduced until experiencing very low outdoor air temperatures, when the motors could cycle on and off.

The Walmart site used VHP control with low ambient control that activated roughly based on an outdoor temperature of $55^{\circ} \mathrm{F}$. The low ambient control turned off half the condenser motors and prevented refrigerant flow through half the condenser to maintain higher condenser pressure. At temperatures below $20^{\circ} \mathrm{F}$ another control strategy was implemented, which is described in more detail in the report, with the same goal of maintaining a high condenser pressure. This project did not analyze whether VHP control was more efficient compared with CFS control from a net refrigerant system perspective, because the boundaries of this project were limited to the condenser only. 


\section{Evaluation Plan}

\subsection{Evaluation Design}

Table 3 summarizes the baselines and energy-efficiency measures (EEMs) that were evaluated for this demonstration. All results were reported for annual energy savings. Table 4 summarizes the qualitative performance objectives that were documented throughout the demonstration.

Table 3. Baseline and Energy-Efficiency Measures Evaluated for Annual Energy Savings

\begin{tabular}{lllll}
\hline Scenario & Baseline Control & EEM Control & Baseline Motor & EEM Motor \\
\hline 1 & CFS & CFS & Induction & HRSR \\
2 & VHP & VHP & Induction & HRSR \\
3 & CFS & VHP & Induction & Induction \\
4 & CFS & VHP & Induction & HRSR \\
\hline
\end{tabular}

Table 4. Qualitative Performance Objectives

\begin{tabular}{lll}
\hline $\begin{array}{l}\text { Performance } \\
\text { Objectives }\end{array}$ & Performance Metrics & $\begin{array}{l}\text { Preliminary } \\
\text { Performance Target }\end{array}$ \\
\hline Safe operation & $\begin{array}{l}\text { Number and type of } \\
\text { maintenance requests }\end{array}$ & $\begin{array}{l}\text { No reductions in store or } \\
\text { equipment operations }\end{array}$ \\
Reliability & Run time & $\begin{array}{l}\text { No failures with the } \\
\text { HRSR motor }\end{array}$ \\
\hline
\end{tabular}

\subsection{Test Bed Site}

The Lakeside Walmart site features a central refrigeration system configured into two racks each with a low temperature and medium temperature evaporator and a common discharge header. Rack A and Rack B are entirely independent of each other. In the original configuration, Rack A had 10 1.5-horsepower condenser fan motors controlled by one variable frequency drive (VFD), and Rack B had eight 1.5-horsepower condenser fan motors controlled by a separate VFD. Half of the induction motors were replaced with HRSR motors. Individual power electronic drives were installed for each HRSR motor, and individual controllers were installed for each rack specifically for the HRSR motors.

Figure 1 illustrates the differences in setup between the induction and HRSR motors, with one VFD controlling several induction motors compared with a single power electronic drive for each HRSR motor. 


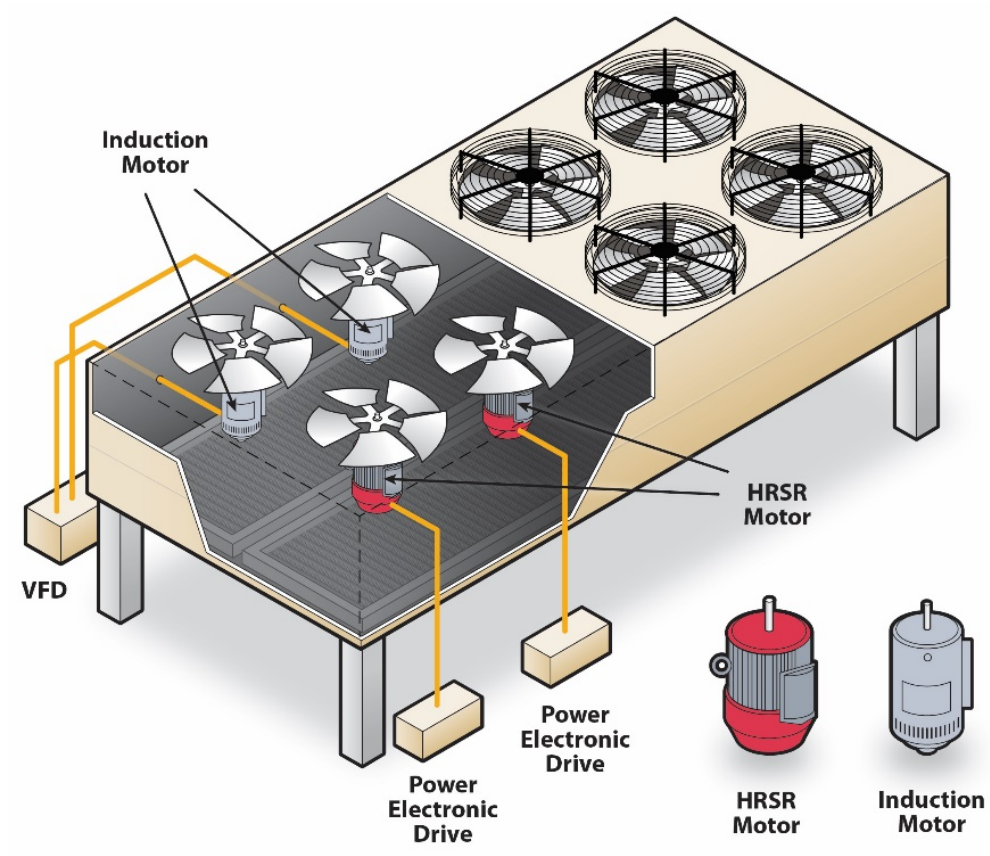

Figure 1. Illustration of the installation of the HRSR motors for a supermarket condenser

Figure 2 further illustrates the specific number of motors for each rack and circuit. Both racks had two circuits for the condenser that could be individually shut off for low ambient temperature control. These circuits were labeled as 1 and 2 in Figure 2. Nine HRSR motors were installed on Circuit 2, while the legacy motors remained on Circuit 1 for both Racks A and B. Circuits 1 or 2 could be isolated on each rack via the operation of a split valve. This split valve was only activated for low ambient temperature control to maintain a higher condenser pressure. Tachometer installation locations were also installed on specific motors, as shown in Figure 2, to monitor motor speeds.

The legacy condenser used VHP control, which adjusted the condenser motor speed based on the $O A_{T}$ and condenser pressure. The two legacy VFDs were configured with the VHP control algorithms and low ambient control algorithms to collectively modulate all condenser motors in each rack. The legacy VFDs also operated the split valves for low ambient control. To allow the HRSR motor controllers to match the legacy control, a control signal providing the fan speed was sent from the legacy VFDs to the HRSR motor controllers via a 4-20 milliampere signal wire. This effectively bypassed the condenser fan shutoff for Circuit 2 during low ambient control, ensuring that all condenser motors were operating regardless of ambient temperature. 


\section{Lakeside Walmart Building}

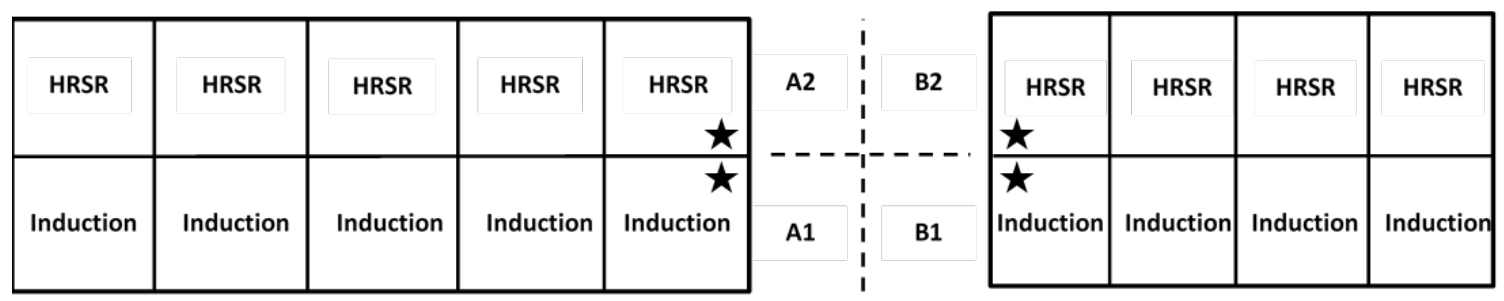

Indicates location of a tachometer.

Figure 2. Condenser rack configuration after installation of the HRSR motors

At the site, several parties coordinated work. As shown in Table 5, the National Renewable Energy Laboratory (NREL) developed the measurement and verification plan. VaCom Technologies installed sensors needed for the legacy system and was the data manager for all legacy measurements. Software Motor Company (SMC) installed sensors for the HRSR motors based on NREL and Walmart requirements. This resulted in two databases that had to be combined in postprocessing. Walmart provided the site for the field demonstration and performed the work to install the HRSR motors, power electronic drives, and controllers on-site.

Table 5. Coordination and Responsibilities by Organization

\begin{tabular}{lll}
\hline Organization & Description & Responsibilities \\
Walmart & $\begin{array}{l}\text { Building owner } \\
\text { Equipment owner }\end{array}$ & $\begin{array}{l}\text { Coordinated and financed work on the project, } \\
\text { including data acquisition system changes }\end{array}$ \\
SMC & $\begin{array}{l}\text { HRSR motor manufacturer } \\
\text { HRSR motor data acquisition } \\
\text { manager }\end{array}$ & $\begin{array}{l}\text { Helped install the EEM; managed data collection } \\
\text { of the high rotor pole switched reluctance motor } \\
\text { (HRSRM) system }\end{array}$ \\
VaCom & $\begin{array}{l}\text { Legacy data acquisition } \\
\text { manager }\end{array}$ & $\begin{array}{l}\text { Installed new sensors as needed for the legacy } \\
\text { system; provided data for the legacy system }\end{array}$ \\
NREL & $\begin{array}{l}\text { Project leader } \\
\text { Data analyzer }\end{array}$ & $\begin{array}{l}\text { Developed the project plan and coordinated } \\
\text { project activities; collected baseline and HRSR } \\
\text { motor system data and performed analysis to } \\
\text { determine results }\end{array}$ \\
& &
\end{tabular}

\subsection{Methodology}

\subsubsection{Quantitative Study Design}

The original plan to estimate annual energy savings was to directly compare the energy consumption of the induction and HRSR motors and extrapolate to annual energy savings. Unfortunately, it was difficult to maintain the same motor speeds for the legacy and HRSR motors with the VHP control signal, because the legacy motors were operating above nameplate motor speed. This issue was not discovered until late in the project because of the issues with the tachometers reading correctly. Therefore, a new approach was taken in which all of the motors were manually controlled to maintain that the same speeds and power measurements were taken at equal speed increments across the operating range. 
Table 6 identifies the measurements, responsible parties, and the type of instruments. All measurements were recorded every minute, and there were two types of speed measurements. The tachometers measured both legacy and HRSR motor speeds, and the HRSR motors used an internal speed measurement. The internal measurements were used during the validation of measurement phase to determine when the tachometers were misreading. Thanks to the internal measurement, it was found that sunlight reflections off the fan blades caused misreadings that were magnitudes of order off the expected values. Therefore, shading that did not inhibit condenser flow was installed around the tachometers to reduce misreadings.

Both VaCom and SMC measured power for an entire circuit, including the inverters/drivers and the controllers used to control each circuit. This resulted in the total power required for the baseline and for the EEM.

Table 6. Monitoring and Instrumentation for a Walmart Refrigeration System in Store 5957

\begin{tabular}{|c|c|c|c|c|c|}
\hline Type of Measurement & Units & $\begin{array}{l}\text { Quantity of } \\
\text { Measurements }\end{array}$ & $\begin{array}{l}\text { Instrument } \\
\text { Owner }\end{array}$ & Phase & Instrument \\
\hline $\begin{array}{l}\text { Condenser Circuit } 2 \\
\text { power (HRSR motors) }\end{array}$ & $\mathrm{kW}$ & 2 & SMC & $\begin{array}{l}\text { Validation and } \\
\text { steady state }\end{array}$ & WattNode \\
\hline $\begin{array}{l}\text { Condenser Circuit } 1 \\
\text { power (induction motors) }\end{array}$ & kW & 2 & VaCom & Annual & Veris \\
\hline Condenser pressure & psi & 2 & VaCom & Annual & Kele PTX1-10 \\
\hline Outdoor air temperature & ${ }^{\circ} \mathrm{F}$ & 1 & VaCom & Annual & Relevant RTD \\
\hline $\begin{array}{l}\text { Condenser inlet } \\
\text { temperature }\end{array}$ & ${ }^{\circ} \mathrm{F}$ & 4 & VaCom & $\begin{array}{l}\text { Validation and } \\
\text { steady state }\end{array}$ & Relevant RTD \\
\hline $\begin{array}{l}\text { Fan speed (legacy and } \\
\text { HRSRM) }\end{array}$ & rpm & 4 & VaCom & $\begin{array}{l}\text { Validation and } \\
\text { steady state }\end{array}$ & $\begin{array}{l}\text { LED } \\
\text { tachometer }\end{array}$ \\
\hline HRSRM fan speed & rpm & 9 & SMC & $\begin{array}{l}\text { Validation and } \\
\text { steady state }\end{array}$ & Internal \\
\hline
\end{tabular}

Note: $\mathrm{kW}=$ kilowatt, $\mathrm{psi}=$ pounds per square inch, ${ }^{\circ} \mathrm{F}=$ Fahrenheit, $\mathrm{rpm}=$ revolutions per minute, $\mathrm{RTD}=$ resistance temperature detector

Three periods of testing were recorded based on three objectives, as shown in Table 7 . The steady-state data period was after the validation test period, because the original plan was to use only the validation data. However, differences in motor speed prohibited use of the validation data for a direct comparison, as described previously. Therefore, they were instead used as a validation data set.

Table 7. Description of Different Test Periods

\begin{tabular}{lll}
\hline Test Period & Objective & Dates \\
\hline Baseline data & Use annual data to determine annual savings. & Nov. 4, 2016-Nov. 4, 2017 \\
Validation data & Validate induction and HRSR motor relationships. & Dec. 1, 2017-Feb. 1, 2018 \\
Steady-state data & $\begin{array}{l}\text { Determine relationship between induction and } \\
\text { HRSR motor power at different motor speeds. }\end{array}$ & Feb. 2-12, 2018 \\
& & \\
\hline
\end{tabular}


The baseline data test period was recorded before installing the HRSR motors. These data were used to determine the baseline annual energy consumption for VHP control.

During the validation testing period, Circuit 1 for Racks A and B maintained VHP control using the legacy algorithms. The HRSR motors followed the VFD signal for each rack. As mentioned previously, low ambient temperature control was altered so that the Circuit 2 fans remained on, allowing for a comparison between induction and HRSR motors during low ambient temperature control. The split valve still activated, preventing refrigerant flow through Circuit 2 during low ambient temperature control.

During steady-state testing, a Walmart technician adjusted the VFD frequency from 5 hertz $(\mathrm{Hz})$ to $60 \mathrm{~Hz}$ in $5-\mathrm{Hz}$ increments every hour over 10 days. With these data, it was possible to develop condenser power curves for the induction and HRSR motor based on motor speed.

\subsubsection{Qualitative Study Design}

Qualitative objectives were analyzed based on discussions with the Walmart technicians, who installed and maintained the refrigeration system. Run-time data were also analyzed to determine if the HRSR motors ever failed.

\subsubsection{Data Analysis}

\subsubsection{Steady-State Data Set}

It became apparent during the first data collection that (1) the tachometers were often reading incorrectly and (2) the HRSR motor and legacy motor were not at equivalent speeds. Both observations are shown in Figure 3. A large amount of the steady-state data was removed either because motor speeds measured over the maximum of $870 \mathrm{rpm}$ (tachometer misreading) or because the rpm measurements between different sensors didn't match. More information is provided in Appendix A, Table 17, about the different types of prefiltering. The main goal of the prefiltering was to ensure that the viable data were kept while removing obvious outliers. After applying the prefiltering, the relationship between HRSR and legacy motor speed was calculated. There was a 3\%-4\% difference in rpm. This was because the HRSR motors had been programed to expect that the legacy motors had a maximum speed of $850 \mathrm{rpm}$, when in reality - because of low torque - the maximum legacy speed was $870 \mathrm{rpm}$. As a result of the speed misreadings and the differences in legacy and HRSR motor speed, the team decided to determine the correlation between speed and power for both legacy and HRSR motors to correct for these issues rather than complete a direct comparison of energy savings. 

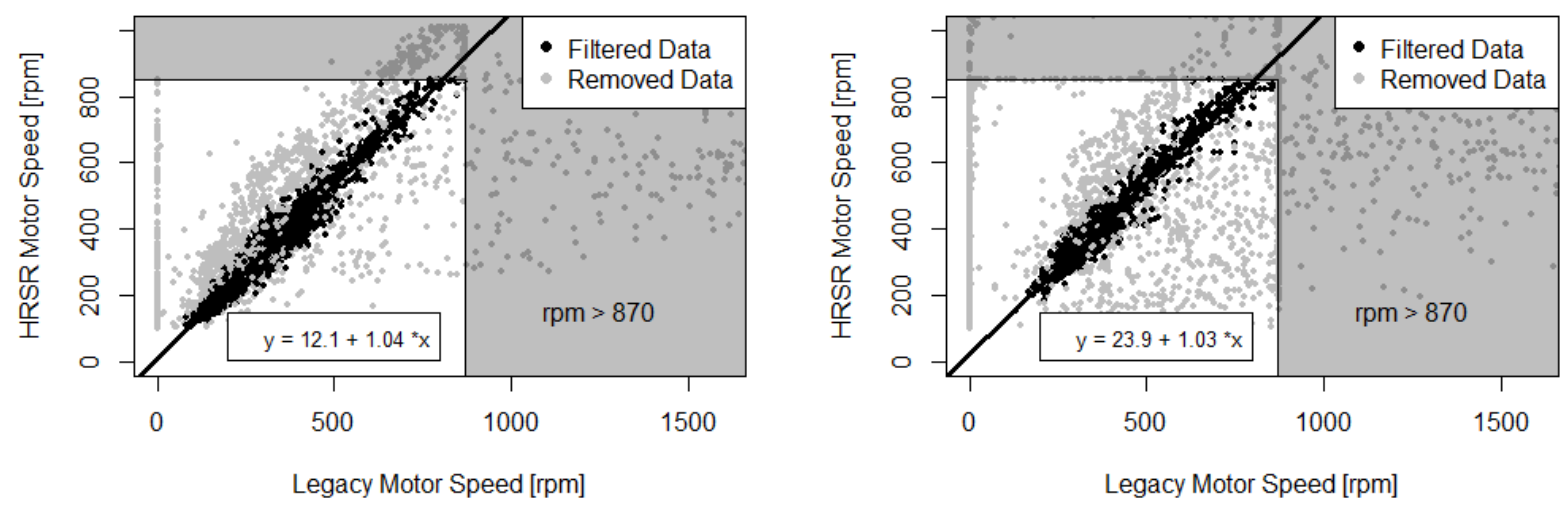

Figure 3. Steady-state data set comparison of HRSR and legacy motor speeds for (left) Rack A and (right) Rack B

Models for both the legacy and HRSR motors were developed using the steady-state data set following Equation 1 with the prefiltered data:

$$
P=n_{\text {motor }}\left[\left(\mathrm{a} \mathrm{rpm}+\mathrm{b} \mathrm{rpm}^{2}\right) \mathrm{rpm}^{\mathrm{n}}+\mathrm{c}\right]
$$

- $\mathrm{P}$, the circuit power (i.e., Circuit 1 for Rack A is the legacy power)

- $n_{\text {motor }}$, the number of motors

- $\quad$ rpm, the motor speed in revolutions per minute

- $\mathrm{n}$, the exponential power

- $\quad \mathrm{a}-\mathrm{c}$, coefficients for the curve fit

where the inverter/driver power was modeled as a quadratic equation related to motor speed, and the motor power was modeled as motor speed to the power $n$. Various values of $n$ in the range of 0-3.5 were analyzed. For each value of $\mathrm{n}$, a least squares regression was performed to determine the coefficients a-c (Appendix A, Table 16). To determine the number of curves that were needed to describe Rack A and Rack B, a t test was completed at each frequency when Rack A and Rack B were set to the same frequencies. The various motor speed measurements were compared to determine which rpm measurements (legacy or HRSR motor) were from a different population. It was shown for all $\mathrm{t}$ tests performed from $5 \mathrm{~Hz}$ to $60 \mathrm{~Hz}$ that the legacy $\mathrm{A}$ and $\mathrm{B}$ rack speed measurements were statistically different; however, the HRSR motor speeds were not statistically different. Therefore, two separate power curves were created for legacy motors for Rack A and Rack B, and one curve was created that represented the HRSR motors for Rack A and Rack B. The data also showed that the legacy and HRSR motor speed measurements were from different populations because of the reasons described previously. 
Regression was performed with the steady-state data considering two factors: the subset of data within the steady-state data and the value for the exponent $n$ in Equation 1. These factors are described further below.

- $\quad$ Filtering

○ No filtering: Remove no data (besides what had been removed via prefiltering).

○ Transient filtering: Remove all data besides the intervals when the heating, ventilating, and air-conditioning (HVAC) technician was manually adjusting the VFD frequencies from $5 \mathrm{~Hz}$ to $60 \mathrm{~Hz}$ for Rack A and Rack B.

- Exponent $\mathrm{n}$ : There were 36 different values for $\mathrm{n}$ ranging from 0 to 3.5 at 0.1 intervals.

This resulted in 72 possibilities for each of the three models (Legacy A, Legacy B, and HRSR for both racks). All possible individual models were evaluated by comparing the root mean square error (RMSE) and normalized mean bias error (NMBE) with the measured power. Every model maintained RMSE below 0.085 and an NMBE within $\pm 1 \mathrm{e}-16$, indicating that all variations of the three models fit the steady-state data well. Therefore, it was decided to pick the best models based on determining the HRSR power as a function of legacy power with the validation data set as described in the next section.

\subsubsection{Validation Data Set}

The validation data set was used to validate both the low ambient temperature control and the power curve models. The low ambient temperature control model was first validated, followed by the power curves for legacy and HRSR motors.

\subsection{Low Ambient Temperature Control}

As shown in Equation 1, the number of motors was an important variable in determining annual energy savings. Low ambient temperature control shuts off refrigerant flow and the condenser fan motors for Circuit 2 and, therefore, directly affects the number of motors that are running. During steady-state and validation test periods, low ambient temperature control shut off refrigerant flow, but it did not turn off the motors for Circuit 2. However, for the annual baseline data, low ambient temperature control was fully operational, and the number of motors changed. To determine the motor count, it was necessary to find an indicator that predicted low ambient temperature control.

Several indicators were created based on the validation data set as the number of motors was known and activation of low ambient temperature control could be quickly determined via the Circuit 2 condenser inlet temperature $\left(\mathrm{Cin}_{T 2}\right) . \mathrm{Cin}_{T 2}$ reacted quickly when refrigerant flow was stopped, dropping from the compressor discharge temperature $\left(140^{\circ} \mathrm{F}-160^{\circ} \mathrm{F}\right)$ to ambient outdoor temperature within minutes when the low ambient temperature control was activated. $\mathrm{Cin}_{T 2}, O A_{T}$, and the difference of Circuit 2 condenser inlet temperature $\left(\operatorname{Cin}_{T 2, D i f f}\right)$ between time steps were used in combination as the ground truth measurement. Because the $\mathrm{Cin}_{T 2}$ sensor was only installed after the HRSR motors were installed, it could not be used as an indicator for the annual data analysis. Therefore, five split valve indicator models were compared with the ground truth indicator. More detailed information of these models is in Appendix A, Table 18. 
The accuracy of each split valve indicator model is shown in Table 8 as well as the false positive ratio (FPR) and the false negative ratio (FNR). FPR indicates how often the model predicted that low ambient temperature control was activated when in reality it was not activated. FNR indicates how often the model predicted that low ambient control was not activated when in reality it was activated.

Table 8. Low Ambient Temperature Control Models and Their Accuracy

\begin{tabular}{|c|c|c|c|c|c|c|c|}
\hline \multirow{2}{*}{$\begin{array}{l}\text { Split Valve } \\
\text { Type }\end{array}$} & \multirow{2}{*}{$\begin{array}{l}\text { Independent } \\
\text { Variables }\end{array}$} & \multicolumn{3}{|l|}{ Rack A } & \multicolumn{3}{|l|}{ Rack B } \\
\hline & & Accuracy & FPR & FNR & Accuracy & FPR & FNR \\
\hline SVT & $\begin{array}{l}\operatorname{Cin}_{T 2}, O A_{T}, \text { and } \\
\operatorname{Cin}_{T 2, D i f f}\end{array}$ & \multicolumn{6}{|c|}{ Ground Truth Indicator Model } \\
\hline SV1 & $O A_{T}$ and $\operatorname{Cond}_{T D}$ & $88.1 \%$ & $0.6 \%$ & $11.2 \%$ & $94.9 \%$ & $1.9 \%$ & $3.1 \%$ \\
\hline SV2 & $O A_{T}$ & $90.7 \%$ & $2.3 \%$ & $6.9 \%$ & $91 \%$ & $2.6 \%$ & $6.3 \%$ \\
\hline SV3 & $D i s_{P r}$ & $94.5 \%$ & $3.7 \%$ & $1.6 \%$ & $86.0 \%$ & $4.3 \%$ & $8.8 \%$ \\
\hline SV4 & $\begin{array}{l}\operatorname{Dis}_{P r}, O A_{T}, \text { and } \\
\operatorname{Cond}_{T D}\end{array}$ & $89.8 \%$ & $1.0 \%$ & $9.2 \%$ & $44.0 \%$ & $0.6 \%$ & $55.2 \%$ \\
\hline
\end{tabular}

Note: $\mathrm{SV}=$ split valve, $\operatorname{Cond}_{T D}=$ legacy condenser temperature difference, $\operatorname{Di}_{P r}=$ discharge pressure

SV3 and SV1 were chosen as the indicator models for low ambient temperature control for Rack A and Rack B, respectively, because they had the highest overall accuracy for both racks. The low ambient temperature control model was used for all four scenarios.

\subsection{Validation of Legacy and High Rotor Pole Switched Reluctance Motor Power Curves}

As discussed in Section 2.3.3.1, power curve permutations needed to be chosen for the three models. Because individual fits with the steady-state data worked well, the team determined that the best way to select the most optimized variation was to compare predicted and calculated HRSR motor power as both legacy and HRSR motor power curves to predict HRSR motor power as shown in Figure 4. This process was also important for the annual data set, because motor speed was not recorded over the annual data period. Therefore, predicting the HRSR motor power as a function of legacy power was the best path for calculating energy savings. 


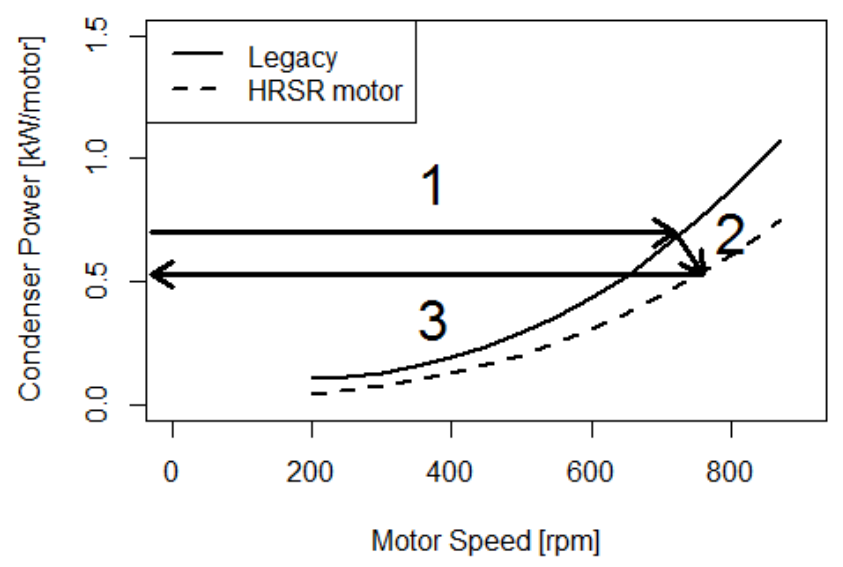

Figure 4. Illustration of the three-step process for predicting the HRSR motor power to validate the power models for the validation data set only

- Step 1: Legacy condenser power was converted to legacy rpm by finding the root of Equation 1 , where a-c were previously fitted coefficients, and $\mathrm{P}$ was the legacy condenser power.

- Step 2: Legacy motor speed was converted to HRSR motor speed. For the validation data set, it was already shown that legacy and HRSR motor speed were statistically different. Therefore, a linear regression was applied in Step 2 to convert between legacy and HRSR motor speed, as shown in Figure 4. Note: Rack A and Rack B were not treated as the same, because they are independent systems with separate VFDs.

- Step 3: The HRSR motor speed was converted to HRSR motor power using Equation 1.

Calculating HRSR motor power with only the legacy power as an input required both the legacy and HRSR curves. Therefore, accounting for the filtering and exponent possibilities for two curves resulted in 5,194 possibilities for each rack. Forty percent of the possible permutations were analyzed to determine patterns. The HRSR motor power curve factors were analyzed first, because the same curve would be used for both racks. Figure 5 illustrates the NMBE for the HRSR motor power based on the two factors previously discussed, namely additional filtering and the exponent $\mathrm{n}$.

Rack B displayed two noticeable results. The first result was that filtering out transient data increased the bias of the HRSR motor power. The second result was that the bias was minimized for an exponent of 1.3. No similar patterns were found for Rack A; however, because the same curve was used for both racks, Rack A also used 1.3 for the exponent $\mathrm{n}$ and included all the transient data for the regression. The RMSE was also calculated; however, it did not vary significantly based on the different factors for the power curves. 

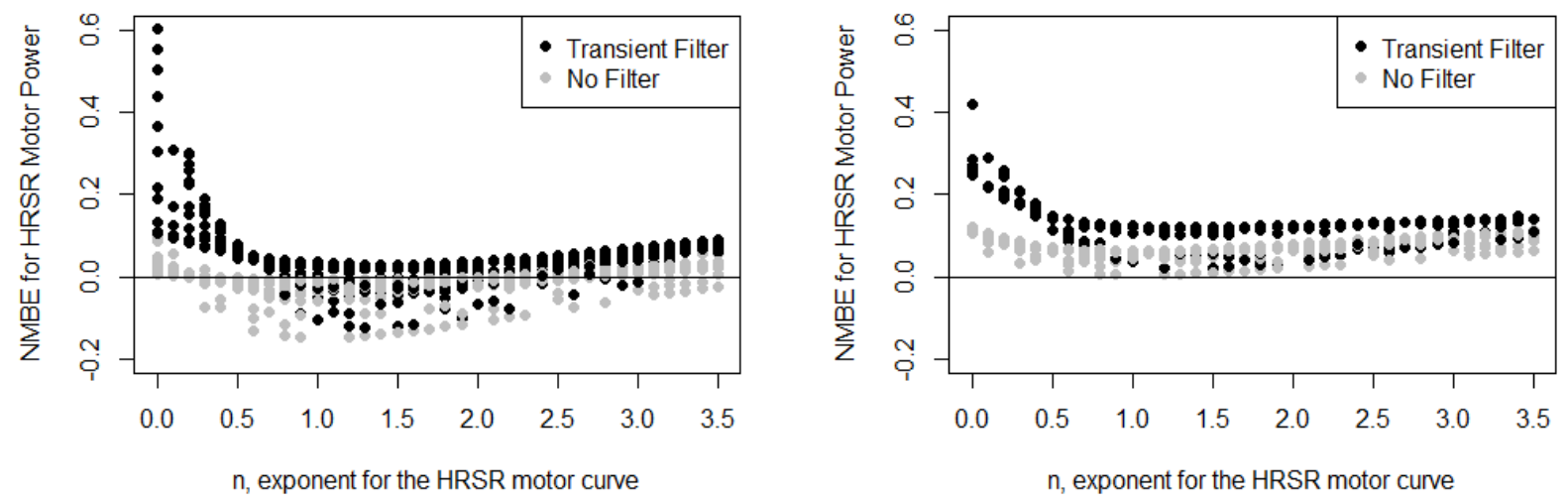

Figure 5. Range of NMBE values for HRSR motor power as a function of the exponent for (left) Rack $A$ and (right) Rack $B$

After determining the factors for the HRSR motor power curve, another design of experiments was run focused on finding the most optimized legacy exponents with the HRSR motor power curve factors fixed. From this design of experiments, the legacy exponents and the filtering factor were determined as well. Figure 6 depicts the NMBE for both racks as a function of the legacy exponent. For both racks, the factors were determined that reduced the biased error and maintained RMSE within reasonable levels. As before, the RMSE did not change significantly; however, the error for Rack B was minimized with the legacy exponent of zero. Although not discernable visually, Rack A error was minimized at a legacy exponent of 1.3.
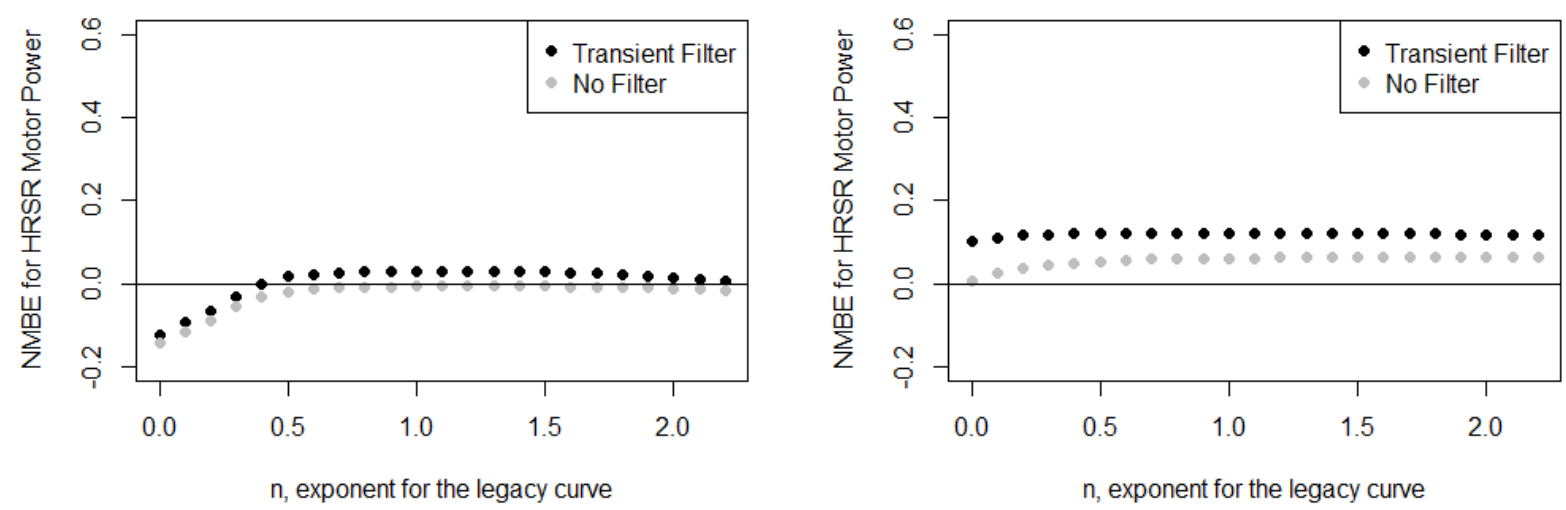

Figure 6. Range of NMBE values for the HRSR motor power as a function of the exponent for the legacy curves for (left) Rack A and (right) Rack B

The final permutations selected for all three power curve models are shown in Table 9. All three power curves used did not filter the data to remove transient behavior. Because the parameters of Equation 1 were estimated jointly, the best fit model accurately represents the relationship between fan speed and VFD input power, but it does not necessarily represent realistic values of coefficients $\mathrm{a}, \mathrm{b}, \mathrm{c}$, and $\mathrm{n}$ for consideration of VFD conversion losses and the fan curve 
separately. This is illustrated, for instance, by the best fit value of $n=0$ for Legacy B.

Coefficients a-c described in Equation 1 are in Appendix A, Table 16.

Table 9. Chosen Parameters for Power Curves Describing Legacy and High Rotor Pole Switched Reluctance Motor Relationships to Speed

\begin{tabular}{llll}
\hline Parameters & Legacy A & Legacy B & HRSR Motor A\&B \\
\hline Filter & $\begin{array}{l}\text { No additional filtering } \\
\text { (besides prefiltering) }\end{array}$ & $\begin{array}{l}\text { No additional filtering } \\
\text { (besides prefiltering) }\end{array}$ & $\begin{array}{l}\text { No additional filtering } \\
\text { (besides prefiltering) }\end{array}$ \\
Exponent, $\mathrm{n}$ & 1.3 & 0 & 1.3 \\
\hline
\end{tabular}

After determining the best power curve models, it was possible to determine the power savings as a function of motor speed. Figure 7 illustrates the relationship of power savings versus motor speed. Percent savings increases at lower motor speeds for both Rack A and Rack B.

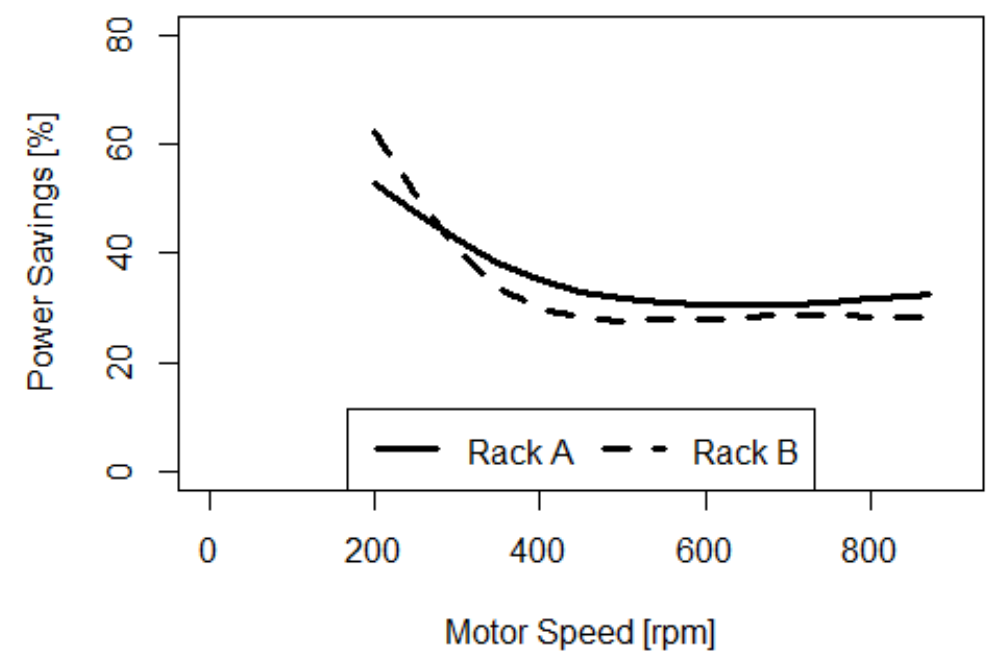

Figure 7. Difference in power between HRSR and legacy motors as a function of motor speed

\subsubsection{Annual Data Set}

The annual data did not have as many sensors as the steady-state and validation data sets. Motor speed measurements and refrigerant temperature measurements (used to determine when low ambient temperature control was activated) were not available. To model the HRSR motor power assuming a complete retrofit of the legacy condenser motors, the legacy condenser power was used as an input following the process laid out in Section 2.3.3.2 with one key exception, as illustrated in Figure 8. The legacy and HRSR motor speeds were assumed equal for the annual data set, as would have been the case for an actual retrofit of the condenser motors. This assumption was deemed appropriate, because both Circuit 1 and 2 received the same speed control signal from the VFD during normal operation. Any future motor hardware replacement would also presumably use approximately the same fan speed control. 

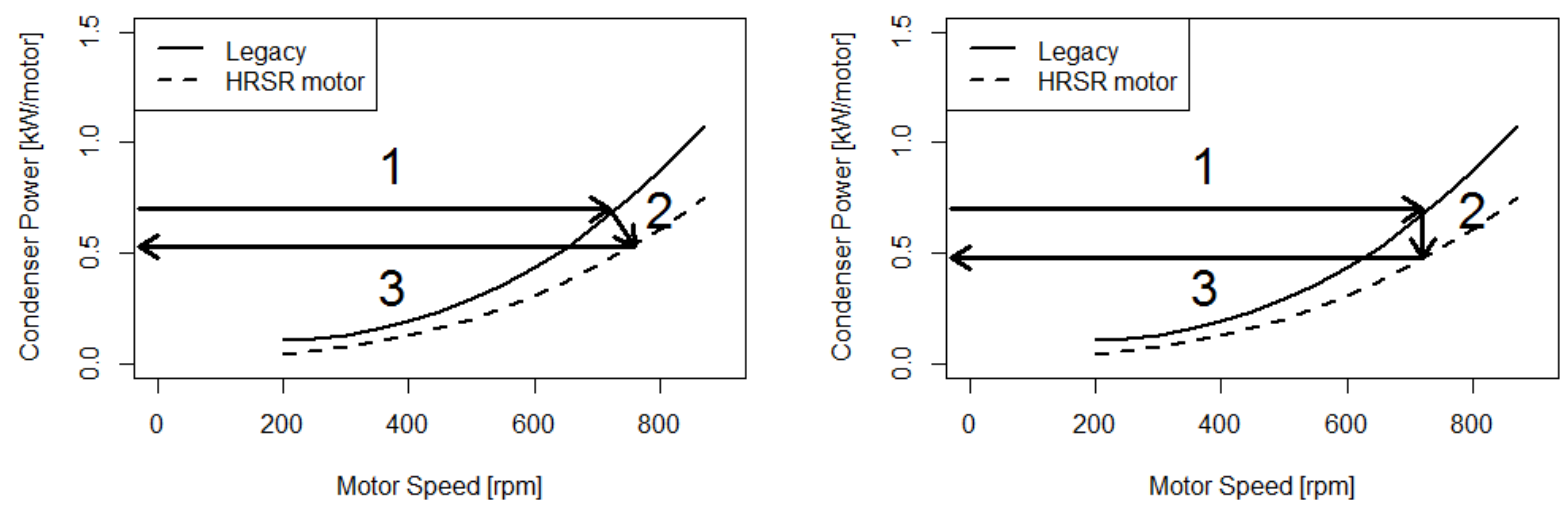

Figure 8. Illustration comparing the three-step process to calculate HRSR motor power for (left) the validation data set and (right) the annual data set

Ambient temperature control was also fully operational, shutting off half the condenser motors when activated. The model to predict this control required both outdoor air temperature and discharge compressor pressure, as described in Section 2.3.3.2.

The power values for the legacy condenser and the HRSR motors were summed to get annual energy consumption. Annual energy consumption was used as the final key metric to determine EEM savings. Two issues had to be overcome with annual data to get an accurate energy consumption estimate. First, another low ambient temperature control had to be modeled; second, missing data had to be accounted for.

\subsection{Extremely Low Ambient Temperature Control}

Looking at the annual data in Figure 9, it was found that another control strategy was applied at $20^{\circ} \mathrm{F}$ and below. Especially for Rack A, it is clearly visible that the condenser power reduces below $20^{\circ} \mathrm{F}$ and again below $15^{\circ} \mathrm{F}$. 

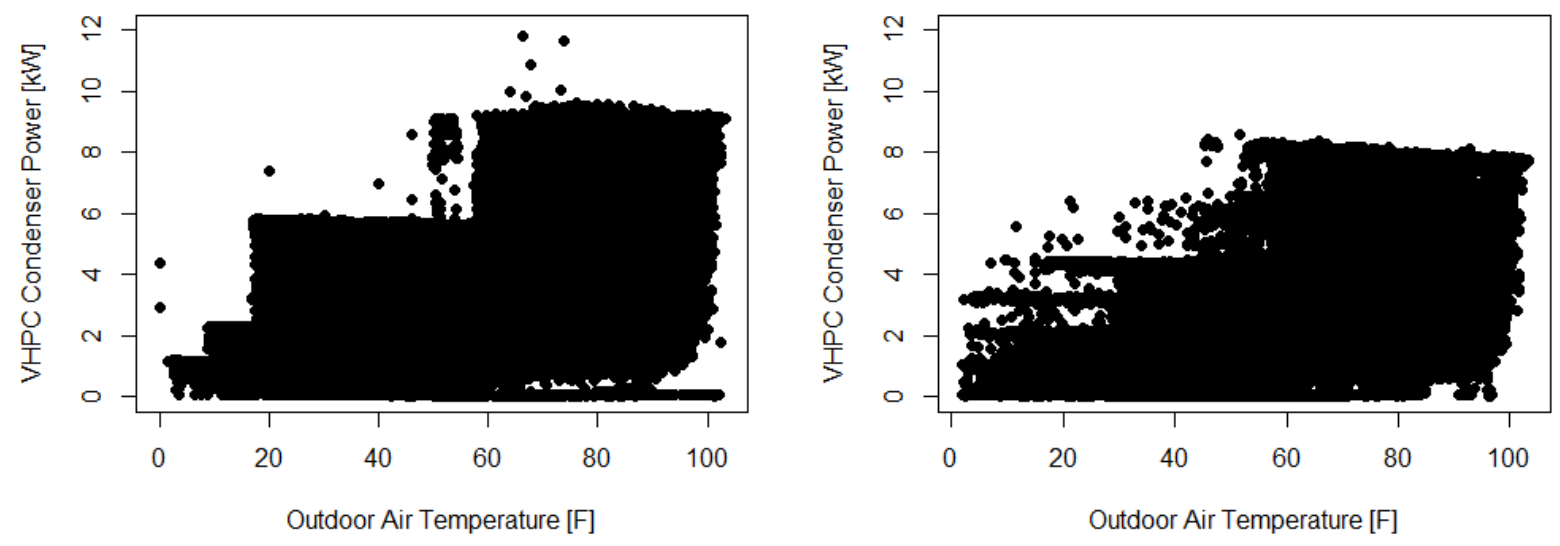

Figure 9. Condenser power versus outdoor air temperature using VHP control for (left) Rack $A$ and (right) Rack B (Note: VHPC = variable head pressure control.)

Table 10 illustrates the same point by documenting the average condenser power as a percent of maximum condenser power and the standard deviation of the condenser power. Standard deviation remains low up to $20^{\circ} \mathrm{F}$, indicating a different control strategy that only uses outdoor ambient temperature compared with VHP control, which also uses condenser pressure. For Scenario 2, this control strategy does not need to be modeled, because the legacy condenser power was used as the input to calculate HRSR motor power and it was already reduced as shown in Figure 9. For CFS control, this strategy was modeled as fan cycling, and the condenser power was reduced to $20 \%$ and $17 \%$ below $15^{\circ} \mathrm{F}$ for Rack A and Rack B, respectively. The condenser power was also reduced to $33 \%$ and $27 \%$ between $15^{\circ} \mathrm{F}$ and $20^{\circ} \mathrm{F}$ for Rack $\mathrm{A}$ and Rack B, respectively. This reduction in power emulated what could potentially happen for CFS control, where all motors would cycle to maintain discharge pressure.

Table 10. Temperature Ranges and Power Patterns for Extremely Low Ambient Temperature Control

\begin{tabular}{l|l|l|l|l}
\hline \multirow{2}{*}{$\begin{array}{l}\text { Temperature } \\
\text { Range ( }\end{array}$} & \multicolumn{2}{|l|}{ Rack A } & Rack B & \multicolumn{2}{l}{} \\
\cline { 2 - 5 } & $\begin{array}{l}\text { Condenser Power } \\
\text { Percent of Maximum }\end{array}$ & $\begin{array}{l}\text { Standard } \\
\text { Deviation }\end{array}$ & $\begin{array}{l}\text { Condenser Power } \\
\text { Percent of Maximum }\end{array}$ & $\begin{array}{l}\text { Standard } \\
\text { Deviation }\end{array}$ \\
\hline$(0,5]$ & $19 \%$ & $2 \%$ & $14 \%$ & $10 \%$ \\
$(5,10]$ & $20 \%$ & $3 \%$ & $17 \%$ & $6 \%$ \\
$(10,15]$ & $20 \%$ & $5 \%$ & $19 \%$ & $4 \%$ \\
$(15,20]$ & $33 \%$ & $21 \%$ & $27 \%$ & $23 \%$ \\
$(20,25]$ & $49 \%$ & $31 \%$ & $43 \%$ & $36 \%$ \\
\hline
\end{tabular}


The CFS control is illustrated in Figure 10. There are four distinct power levels for CFS control related to:

1. Full speed and all motors running

2. Full speed with low ambient temperature control activated (half of the motors are operational)

3. The first band of low ambient temperature control below $20^{\circ} \mathrm{F}$

4. The lowest power level for CFS control for the lowest temperature ranges for low ambient temperature control below $15^{\circ} \mathrm{F}$.
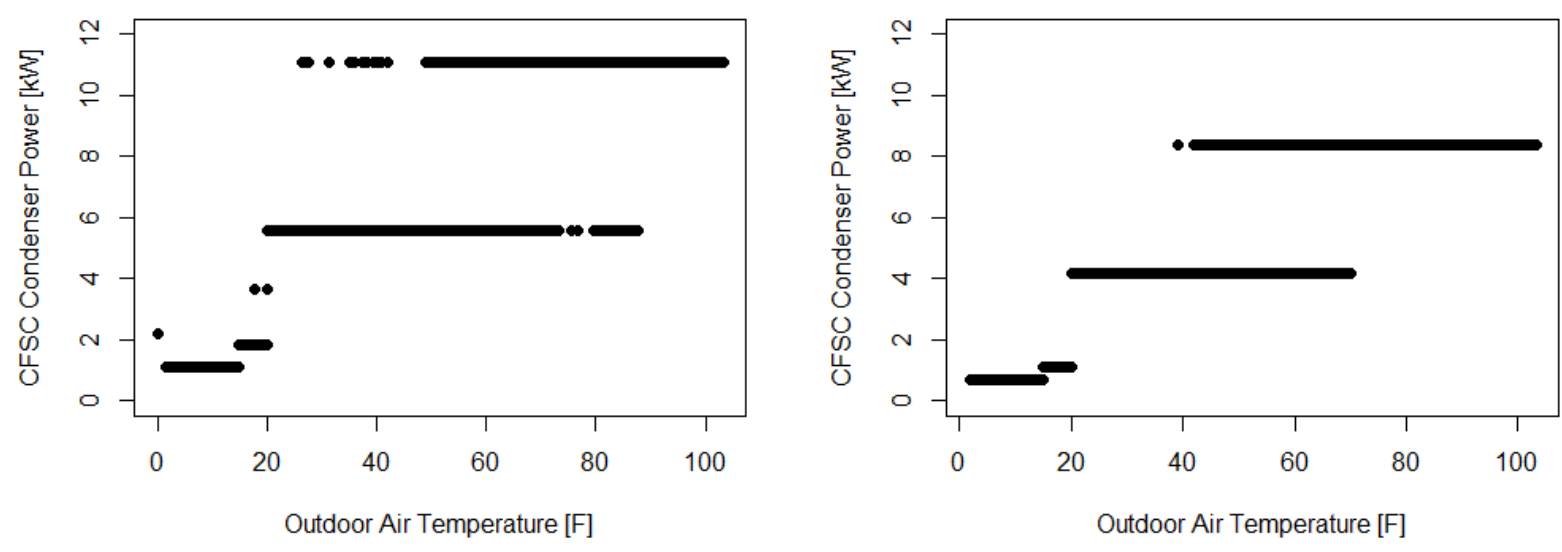

Figure 10. Condenser power versus outdoor air temperature using CFS control for (left) Rack $A$ and (right) Rack B (Note: CFSC = constant fan speed control.)

\subsection{Estimating Missing Data}

Condenser power, $O A_{T}$, and compressor discharge pressure were the three critical measurements for each time step to determine the energy savings and to use with the low ambient temperature control model. Two percent of the annual data was missing one of the three critical measurements at any given time step. Any missing data had to be replaced for these three key measurements. Power measurements were interpolated for a maximum of 5 minutes, while $O A_{T}$ was interpolated for up to 2 hours as the first step for replacement.

Compressor discharge pressure was not interpolated, because it changed sporadically compared with $O A_{T}$. Time steps with missing data after interpolation were replaced with data from another time step with similar outdoor air conditions. Similarly, because the HRSR motor installation took place during the annual test period, all data during the 2-week installation were replaced with a week with comparable energy consumption and average $O A_{T}$ repeated twice. When no $O A_{T}$ data were recorded on the site, weather station KCODENVE110 from Weather Underground was used. Because it was 1 mile away, a correlation was developed to determine 
the temperature at the site based on the weather station data, as shown in Figure 11. All of these steps reduced the missing data to less than $0.25 \%$ of the 525,600 time steps in the annual data.

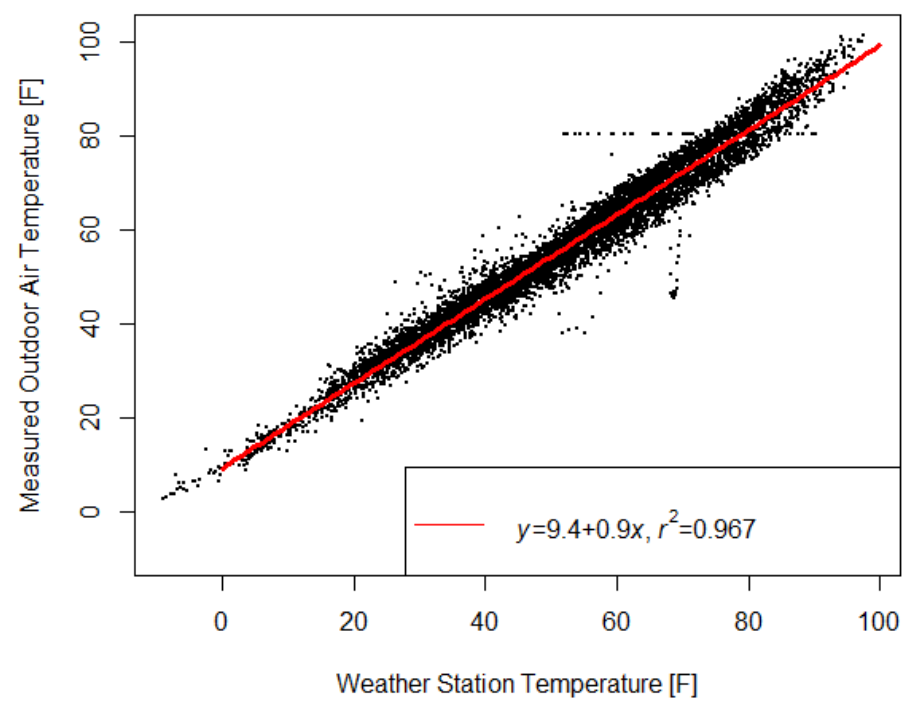

Figure 11. Parity plot between site and Weather Underground station outdoor air temperature

\subsubsection{Uncertainty Analysis}

An uncertainty analysis was performed following the process outlined by ASHRAE Standard Guideline 14 (ASHRAE 2014). As a form of comparison, the power estimate error was also included from the validation data set. The results from the uncertainty analysis are presented in Table 11, and a detailed report on the uncertainty analysis is provided in Appendix B.

Table 11 specifies the uncertainty for energy savings based on a $95 \%$ confidence interval for all four scenarios. Note that Scenario 3 and Scenario 4 have nonsymmetrical error. This is because switching from CFS control to VHP control will create a modest increase in compressor energy consumption, so the actual energy savings would likely be less than reported.

Preliminary model results indicate that compressors would potentially consume $1 \%$ more energy or a $10 \%$ reduction in energy savings. This was used to adjust the uncertainty results; however, it was not used for the energy savings analysis, because it was outside the scope of this project and was not fully vetted. Compressor power consumption will change based on climate, location, and condenser characteristics. Still, it provides an estimate for uncertainty. 
Table 11. Uncertainty Analysis Results

\begin{tabular}{|c|c|c|c|c|c|c|c|c|}
\hline \multirow[b]{2}{*}{ Rack } & \multirow{2}{*}{$\begin{array}{l}\text { EEM } \\
\text { Power } \\
\text { RMSE }\end{array}$} & \multirow{2}{*}{$\begin{array}{l}\text { EEM } \\
\text { Power } \\
\text { NMBE }\end{array}$} & \multirow{2}{*}{$\begin{array}{l}\text { Energy } \\
\text { Error }\end{array}$} & \multirow{2}{*}{$\begin{array}{l}\text { HRSR } \\
\text { Motor } \\
\text { Speed } \\
\text { Standard } \\
\text { Deviation } \\
\text { VHPC }\end{array}$} & \multicolumn{4}{|c|}{$\begin{array}{l}95 \% \text { Confidence Interval for Annual } \\
\text { Energy Savings }\end{array}$} \\
\hline & & & & & Sc. 1 & Sc. 2 & Sc. 3 & Sc. 4 \\
\hline Data Set & Validation & Validation & Validation & Validation & Annual & Annual & Annual & Annua \\
\hline Rack A & 0.26 & -0.0056 & $-0.47 \%$ & $1 \mathrm{rpm}$ & $\pm 2.5 \%$ & $\pm 5.1 \%$ & $\begin{array}{l}+1 \% \\
-11 \%\end{array}$ & $\begin{array}{l}+1 \% \\
-11 \%\end{array}$ \\
\hline Rack B & 0.51 & 0.0080 & $0.38 \%$ & $69 \mathrm{rpm}$ & $\pm 4.6 \%$ & $\pm 60.3 \%$ & $\begin{array}{l}+5 \% \\
-15 \%\end{array}$ & $\begin{array}{l}+14 \% \\
-24 \%\end{array}$ \\
\hline
\end{tabular}

Table 11 documents the validation period energy error as well. For Rack A, the measured energy consumption during the validation period was 646 kilowatt-hour $(\mathrm{kWh})$, while the predicted value was $643 \mathrm{kWh}(-0.47 \%)$. For Rack B, the measured energy consumption was $1,547 \mathrm{kWh}$, while the predicted value was $1,553 \mathrm{kWh}(0.38 \%)$. Because of the large uncertainty for the Rack B Scenario 2 motor speed, the energy results were disregarded and only Rack A results are presented for Scenario 2 in the rest of the paper. This uncertainty was much larger as a result of the standard deviation across all HRSR motors for each time step for Rack B. This error propagated for Rack B Scenario 4 as well; however, the energy savings were more significant, reducing the uncertainty within reasonable levels. 


\section{Demonstration Results}

\subsection{Quantitative Results}

Table 12 shows the annual energy consumption for the baseline. VHP control was measured, while CFS control was modeled.

Table 12. Annual Baseline Performance Results

\begin{tabular}{lll}
\hline Rack & Control Type & $\begin{array}{l}\text { Annual Condenser } \\
\text { Baseline Performance } \\
\text { (kWh/motor) }\end{array}$ \\
\hline Rack A & CFS control & 6,121 \\
Rack B & & 6,252 \\
Rack A & VHP control & 2,641 \\
Rack B & & 2,785 \\
\hline
\end{tabular}

Table 13 shows the performance comparison between the baseline and EEMs. The energy savings for the four scenarios were $29 \%, 33 \%, 57 \%$, and $71 \%$ respectively. Scenario 2 (direct comparison of VHP control) benefited from the increased HRSR motor efficiency at lower rpm ranges to increase the percent energy savings by $4 \%$ versus Scenario 1 (direct comparison of CFS control).

In terms of absolute energy, Scenario 4 saved the most energy, followed by Scenario 3. This is because VHP control reduced energy consumption for both the legacy and HRSR motors significantly. Switching control strategies with induction motors alone saved an average of 3,545 $\mathrm{kWh}$ per motor. Including the HRSR motor efficiency further saved an additional $866 \mathrm{kWh}$ per motor, resulting in a total of 4,411 kWh per motor savings for Scenario 4.

Scenario 3 and switching from CFS control to VHP control were the two scenarios that saved the most energy. Scenario 3 and Scenario 4 energy savings would be less when considering an entire refrigerant system including compressors versus the condenser alone. This is because reduced airflow across the condenser (as a result of reduced motor speed) would increase the refrigerant discharge pressure and the compressor power consumption. Therefore, it is still not clear how much energy VHP control saves from a net refrigerant system perspective, although it is clear looking at the condenser alone that there is significant energy savings. Scenario 1 and Scenario 2 would still see the same amount of absolute energy savings from a net refrigerant system perspective, because the control strategy was the same for both the baseline and EEM, resulting in no change to the compressor energy. 
Table 13. Energy Savings for Rack A and Rack B

\begin{tabular}{lllllll}
\hline Scenario & Rack & $\begin{array}{l}\text { Baseline } \\
\text { Control }\end{array}$ & $\begin{array}{l}\text { EEM } \\
\text { Control }\end{array}$ & $\begin{array}{l}\text { EEM } \\
\text { Motor }\end{array}$ & $\begin{array}{l}\text { Savings } \\
\text { (kWh/motor) }\end{array}$ & $\begin{array}{l}\% \text { Energy } \\
\text { Savings }\end{array}$ \\
\hline 1 & A\&B & CFS & CFS & HRSR & 1,817 & $29 \%$ \\
2 & $A^{1}$ & VHP & VHP & HRSR & 866 & $33 \%$ \\
3 & A\&B & CFS & VHP & Induction & 3,545 & $57 \%$ \\
4 & A\&B & CFS & VHP & HRSR & 4,411 & $71 \%$ \\
\hline
\end{tabular}

${ }^{1}$ Rack B discarded because of the uncertainty analysis (see Appendix B).

Another important consideration is the reduction in demand charges. Because the cost analysis used U.S. Energy Information Administration (EIA) cost per kilowatt-hour, which is a blended cost including all charges from utilities, the demand charges based on the power savings for each EEM were not added to the cost analysis.

However, the kilowatt savings are still important to consider. Table 14 presents the average monthly peak power reduction based on 15-minute intervals over the modeled year. With CFS control only (Scenario 1), the greatest reduction in peak power based on 15-minute values was $0.23 \mathrm{~kW} /$ motor, and for VHP control only (Scenario 2), it was $0.10 \mathrm{~kW} /$ motor for both racks. Scenario 4 saved the most demand at an average of $0.51 \mathrm{~kW} /$ motor. However, as shown by Scenario 3, the majority of this demand savings is attributable to switching control strategies from CFS control to VHP control.

It should be noted again that the compressors will likely increase power consumption for both Scenario 3 and Scenario 4, reducing the potential power reduction. Another consideration when evaluating demand savings is that the peak demand reduction time for the condenser fans may not align with the peak demand for the building as a whole, which would potentially decrease the benefit of these peak demand savings.

Table 14. Average Monthly Peak Power Reduction Based on 15-Minute Intervals for All Four Scenarios

\begin{tabular}{lllll}
\hline Rack & Scenario 1 & Scenario 2 & Scenario 3 & Scenario 4 \\
\hline A & $0.23 \mathrm{~kW} /$ motor & $0.10 \mathrm{~kW} /$ motor & $0.41 \mathrm{~kW} /$ motor & $0.51 \mathrm{~kW} /$ motor \\
B & $0.20 \mathrm{~kW} /$ motor & $0.11 \mathrm{~kW} /$ motor & $0.40 \mathrm{~kW} /$ motor & $0.51 \mathrm{~kW} /$ motor \\
Avg. & $0.21 \mathrm{~kW} /$ motor & $0.10 \mathrm{~kW} /$ motor & $0.41 \mathrm{~kW} /$ motor & $0.51 \mathrm{~kW} /$ motor \\
\hline
\end{tabular}

\subsection{Qualitative Results}

No issues occurred with the HRSR motors. However, during installation, one HRSR motor locked a rotor. A locked rotor alarm was sent to the HRSR motor manufacturer, who shut down the motor. An inspection revealed that a piece of foam had jammed the fan, as shown in Figure 12 . 


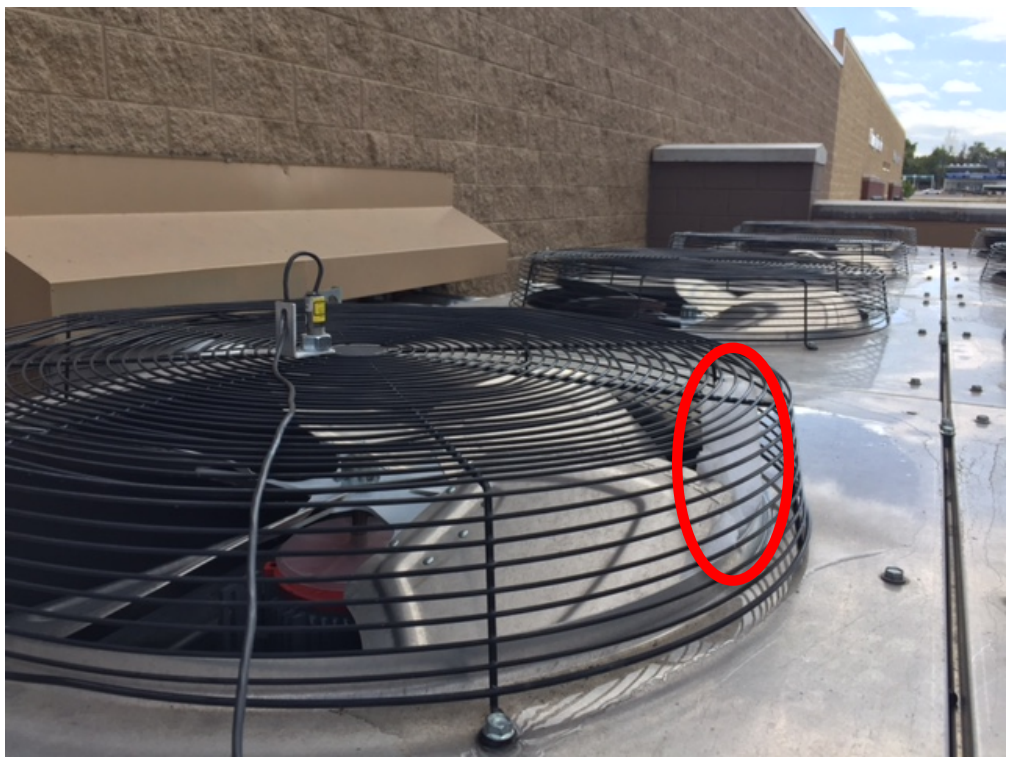

Figure 12. Foam jamming the condenser fan with an HRSR motor installed

The foam was removed, the fan was replaced, and the motor was turned back on. This was an excellent example of the advantages of remote control of individual motors. Without this capability, this issue could have burned out the individual motor and potentially required an emergency repair or replacement. With the HRSR motor system, the motor was turned off, preventing irreparable harm, and the appropriate people were notified to determine the importance of the failure and the appropriate response.

The installation technicians also reported an issue with resonant frequencies during the commissioning of the HRSR motors. To mitigate it, the ramp-up time of the HRSR motors was increased to 1 minute, reducing the likelihood that all motors sped up at the same time, which solved the problem.

\subsection{Cost-Effectiveness}

The installation cost for this project was not tracked; this was not the goal, and the HRSR motor manufacturer did not provide equipment costs. However, a basic economic analysis was performed assuming a simple payback of 3 years, as shown in Table 15. This cost analysis was specifically calculated for the climate and location of this demonstration. Cost analysis may change based on the many different factors.

A complete replacement of all condenser motors (Table 15) was assumed. This analysis was performed using EIA data (U.S. Energy Information Administration 2012) for the cost of electricity. Two costs of electricity were assumed for the analysis to represent a range across the United States. The annual blended cost of electricity per kilowatt-hour was found to be 9.8 cents/kWh in Colorado (representative of many other regions and close to the U.S. average of 10.66 cents/kWh) and 15.8 cents/kWh (representative of New England and California) for 2017. The forecasted cost of electricity for the 3-year payback calculation was adjusted each year based on the EIA forecasted change in electricity cost. 
Table 15. Annual and 3-Year Simple Savings Analysis per Motor for a Complete Replacement

\begin{tabular}{|c|c|c|c|c|c|c|c|c|}
\hline \multirow{2}{*}{ Sc. } & \multicolumn{2}{|l|}{ Control } & \multirow{2}{*}{$\begin{array}{l}\text { EEM } \\
\text { Motor }\end{array}$} & \multirow{2}{*}{$\begin{array}{l}\text { Energy } \\
\text { Savings } \\
\begin{array}{l}\text { (kWh/ } \\
\text { motor) }\end{array}\end{array}$} & \multicolumn{2}{|c|}{$\begin{array}{l}\text { Annual Energy } \\
\text { Savings per Motor }\end{array}$} & \multicolumn{2}{|c|}{$\begin{array}{l}\text { 3-Year } \\
\text { Energy Savings } \\
\text { per Motor }\end{array}$} \\
\hline & Baseline & EEM & & & $\begin{array}{l}(9.8 \\
\text { cents/ } \\
\text { kWh) }\end{array}$ & $\begin{array}{l}(15.8 \\
\text { cents/ } \\
\text { kWh })\end{array}$ & $\begin{array}{l}(9.8 \\
\text { cents/ } \\
\text { kWh) }\end{array}$ & $\begin{array}{l}(15.8 \\
\text { cents/ } \\
\text { kWh) }\end{array}$ \\
\hline 1 & CFS & CFS & HRSR & 1,817 & $\$ 178$ & $\$ 287$ & $\$ 538$ & $\$ 869$ \\
\hline 2 & VHP & VHP & HRSR & 866 & $\$ 85$ & $\$ 137$ & $\$ 256$ & $\$ 414$ \\
\hline 3 & CFS & VHP & Induction & 3,545 & $\$ 347$ & $\$ 560$ & $\$ 1,050$ & $\$ 1,695$ \\
\hline 4 & CFS & VHP & HRSR & 4,411 & $\$ 432$ & $\$ 697$ & $\$ 1,310$ & $\$ 2,110$ \\
\hline
\end{tabular}

The four scenarios ranged from $\$ 85$ to $\$ 697$ annual energy savings for a single motor, while 3year savings ranged from $\$ 256$ to $\$ 2,110$ per motor. Three-year and even 1-year simple paybacks are possible if one is able to completely retrofit a condenser including labor and equipment cost for under the prices documented in Table 15. Considering that the legacy induction motors cost roughly $\$ 440$ each in 2017 (Line Central International 2017), it is clear that the payback incentive for a complete retrofit is best for sites with high costs in electricity and simple legacy condenser controls such as CFS control. It is also likely that simple paybacks of 3-5 years are not possible for complete retrofits with sites with low costs of electricity or sites that already have implemented VHP control. 


\section{Summary Findings and Conclusions}

\subsection{Overall Technology Assessment at Demonstration Facility}

The results from this field retrofit proved that the HRSR motor is a more efficient motor compared with the legacy induction motor. Calculated savings at a Walmart store in Lakeside, Colorado, ranged from $29 \%$ to $71 \%$, depending on several factors, such as better efficiency of the HRSR motor and the VHP control strategy.

In terms of absolute energy savings, the best scenario (Scenario 4) combined both a motor efficiency increase and improved condenser control, resulting in 4,411 kWh/motor/year savings. These savings are optimistic, because the compressor racks will likely spend more energy with VHP control.

The lowest savings occurred when replacing legacy induction motors that were already using VHP control, resulting in only $866 \mathrm{kWh} /$ motor/year savings. The large range in energy savings illustrates the importance of site selection for the best payback options. A simple cost analysis was performed, indicating that a 3-year simple payback would likely be possible for sites with a high cost of electricity.

\subsection{Lessons Learned and Best Practices}

As mentioned in the qualitative results, no issues occurred relating to motor operation. However, resonant vibration issues were found when the motors ramped up at the same time. To mitigate this issue, the ramp-up time for the HRSR motors was increased to 1 minute, reducing the likelihood the motors were ramping up together. Other solutions are available and should be investigated at each install, including avoiding certain motor speeds (this option is available in the HRSR motor controller programming).

Walmart also mentioned the difficulty in installing the power drives for each HRSR motor. The HRSR motor manufacturer has developed a new product in response that combines the power drive with the HRSR motor. This would reduce the installation burden, only requiring installation of the motor and the master controller. This new product will be available for 1-1.5horsepower motors by the summer of 2019.

The project team brainstormed additional unique control strategies during the project and identified three potential energy saving approaches that have yet to be demonstrated. These unique control strategies are intended to be the subject of future study.

Another field demonstration was completed for a 10-horsepower HRSR motor in a pump application for a commercial building. The General Services Administration's Proving Ground program funded this demonstration, and Oak Ridge National Laboratory performed the analysis. The final report from the program is expected summer 2019.

\subsection{Deployment Recommendations}

As a result of the cost analysis, systems with constant speed fans could see financial benefits for a major renovation, especially when implementing VHP control for the retrofit. Sites with low efficiency condenser fan motors from 1-10 horsepower and locations with high electricity prices 
would benefit the most. It is unlikely for systems that already have VHP control that the current HRSR motors and separate power drive would be cost effective considering a 3-year simple payback for major renovation. However, this report completed the analysis for the specific field location at Lakeside, Colorado, for 2017. There are many factors that affect the payback analysis. One factor that was looked at in this report was cost of electricity, which resulted in a significant difference in energy cost savings. Other factors that could affect payback include legacy motor efficiency for the entire range of motor speeds and run time of the motor. 


\section{Appendix A. Research Details}

Table 16 shows the coefficients that were used based on Equation 1 to define the induction and HRSR motor power curves as a function of motor speed.

Table 16. Curve Fits for Legacy and High Rotor Pole Switched Reluctance Motor Power Consumption Based on Equation 1

\begin{tabular}{lllll}
\hline Curve & Coefficient a & Coefficient b & Coefficient c & Power $\mathbf{n}$ \\
\hline Legacy Rack A & $8.090 \mathrm{e}-08$ & $1.130 \mathrm{e}-10$ & $7.827 \mathrm{e}-2$ & 1.3 \\
Legacy Rack B & $-1.055 \mathrm{e}-03$ & $2.272 \mathrm{e}-06$ & $2.430 \mathrm{e}-01$ & 0 \\
EEM Rack A\&B & $8.936 \mathrm{e}-08$ & $4.158 \mathrm{e}-11$ & $2.732 \mathrm{e}-02$ & 1.3 \\
\hline
\end{tabular}

Table 17 describes the prefilters that were used to remove erroneous data from the steady-state data set in preparation for developing power curves as a function of motor speed.

Table 17. Description of Prefilters for the Steady-State Data Set

\begin{tabular}{|c|c|c|c|}
\hline Filter & $\begin{array}{l}\text { Independent } \\
\text { Variables }\end{array}$ & Filter & Inputs \\
\hline Steady state & $\begin{array}{l}\text { start }_{t} \text { and } \\
\text { stop }_{t}\end{array}$ & $\begin{array}{l}\text { Filter }\left(\text { data }_{t} \geq \operatorname{start}_{t} \& \text { data }_{t} \leq\right. \\
\left.\text { stop }_{t}\right)\end{array}$ & $\begin{array}{l}\text { Start and stop times } \\
\text { provided by the HVAC } \\
\text { technician's logs }\end{array}$ \\
\hline rpm outliers & $\begin{array}{l}\text { Legacy }_{\text {rpm }} \\
\text { and } \\
H_{R S R_{\text {rpm,tach }}}\end{array}$ & $\begin{array}{l}\text { Filter }\left(\text { Legacy } y_{\text {rpm }} \leq 870 \mathrm{rpm} \text { and }\right. \\
\left.\quad H R S R_{\text {rpm }, \text { tach }} \leq 850 \mathrm{rpm}\right)\end{array}$ & $\begin{array}{l}\text { Legacy rpm is only } \\
\text { provided by tachometers }\end{array}$ \\
\hline $\begin{array}{l}\text { Same motor } \\
\text { tachometer } \\
\text { versus HRSR } \\
\text { motor internal } \\
\text { measurement }\end{array}$ & $\begin{array}{l}H R S R_{\text {rpm,int }, i} \\
\text { and } \\
H R S R_{\text {rpm,tach }}\end{array}$ & Filter( $\left.0.8 \leq \frac{H R S R_{r p m, t a c h, i}}{H R S R_{r p m, i n t}} \leq 1.2\right)$ & $\begin{array}{l}\text { Where } \mathrm{i}=5 \text { for Rack } \mathrm{A} \\
\text { and } \mathrm{i}=1 \text { for Rack } \mathrm{B} \\
\text { denoting the motor that } \\
\text { the tachometer measured }\end{array}$ \\
\hline $\begin{array}{l}\text { Average of } \\
\text { internal } \\
\text { measurements } \\
\text { of all HRSR } \\
\text { motors versus } \\
\text { HRSR motor } \\
\text { tachometer }\end{array}$ & $\begin{array}{l}\overline{H R S R}_{\text {rpm,int }} \\
\text { and } \\
H R S R_{\text {rpm,tach }}\end{array}$ & $\begin{array}{l}\text { Filter }\left(-50 \leq \overline{H R S R}_{\text {rpm,int }}-\right. \\
\left.H R S R_{\text {rpm,tach }} \leq 50\right)\end{array}$ & \\
\hline $\begin{array}{l}\text { Legacy } \\
\text { tachometer } \\
\text { measurement } \\
\text { versus HRSR } \\
\text { motor } \\
\text { tachometer }\end{array}$ & $\begin{array}{l}\text { Legacy } \\
\text { and } \\
H_{\text {RSR }} \\
\text { rpm,tach }\end{array}$ & Filter( $\left.0.72 \leq \frac{\text { Legac }_{r p m}}{\text { HRSR }_{r p m, i n t}} \leq 1.2\right)$ & \\
\hline
\end{tabular}


Table 18 describes the low ambient temperature control models that were developed. An output of -1 indicates activated, 1 indicates deactivated, and 0 indicates an unknown mode of low ambient temperature control.

Table 18. Additional Details of Low Ambient Temperature Control Models

\begin{tabular}{|c|c|c|c|c|c|c|}
\hline \multirow{2}{*}{ Model } & \multirow{2}{*}{$\begin{array}{l}\text { Independent } \\
\text { Variables }\end{array}$} & \multirow{2}{*}{ Conditional Statement } & \multicolumn{2}{|l|}{ Rack A } & \multicolumn{2}{|l|}{ Rack B } \\
\hline & & & $x_{1}$ & $x_{2}$ & $x_{1}$ & $x_{2}$ \\
\hline SVT & $\begin{array}{l}\operatorname{Cin}_{T 2}, O A_{T} \\
\text { and } \operatorname{Cin}_{T 2, D i f f}\end{array}$ & $\begin{array}{l}\text { If } \mathrm{Cin}_{T 2, D i f f}>15 \text { and } \mathrm{Cin}_{T 2}-O A_{T}>1, \mathrm{y} \\
=1 \\
\text { If } \mathrm{Cin}_{T 2, D i f f}<-2 \text { and } \mathrm{Cin}_{T 2}-O A_{T}>0, \mathrm{y} \\
=-1 \\
\quad \text { Else, } \mathrm{y}=0 \\
\text { If } \mathrm{Cin}_{T 2}-O A_{T}<1.5, \mathrm{y}=-1 \\
\quad \text { Else, } \mathrm{y}=\mathrm{y} \\
\text { If } \mathrm{y}[i-1]=1 \text { and } y[i]=0, \mathrm{z}=1 \\
\text { If } y[i-1]=-1 \text { and } y[i]=0, \mathrm{z}=-1 \\
\text { Else, } \mathrm{z}=\mathrm{y}\end{array}$ & & & & \\
\hline SV1 & $\begin{array}{l}O A_{T} \text { and } \\
\text { Cond }_{T D}\end{array}$ & $\begin{array}{l}\text { If } O A_{T}>70^{\circ} \mathrm{F}, \mathrm{y}=1 \\
\text { If } \operatorname{Cond}_{T D}>x_{1}, \mathrm{y}=-1 \\
\text { Else, } \mathrm{y}=1\end{array}$ & $26^{\circ} \mathrm{F}$ & & $25^{\circ} \mathrm{F}$ & \\
\hline SV2 & $O A_{T}$ & If $O A_{T}>56^{\circ} \mathrm{F}, 1, y=-1$ & & & & \\
\hline SV3 & $D i s_{P r}$ & $\begin{array}{l}\text { If } D_{i s_{P r}}>x_{1}, y=1 \\
\quad \text { If } D i s_{P r}<x_{2}, y=-1, \\
\quad \text { Else, } y=0 \\
\text { If } y[i-1]=1 \text { and } y[i]=0, z=1 \\
\text { If } y[i-1]=-1 \text { and } y[i]=0, z=-1\end{array}$ & 170 psi & 148 psi & 190 psi & $150 \mathrm{psi}$ \\
\hline SV5 & $\begin{array}{l}\operatorname{Dis}_{P r}, O A_{T} \\
\text { and } \operatorname{Cond}_{T D}\end{array}$ & $\begin{array}{l}\text { If } \operatorname{Dis}_{P r}>x_{1} \text { and } O A_{T}<x_{2}, \mathrm{y}=-1 \\
\text { If } \operatorname{Cond}_{T D}>26^{\circ} \mathrm{F}, \mathrm{y}=-1 \\
\text { Else, } \mathrm{y}=1\end{array}$ & $152 \mathrm{psi}$ & $65^{\circ} \mathrm{F}$ & $152 \mathrm{psi}$ & $110^{\circ} \mathrm{F}$ \\
\hline
\end{tabular}




\section{Appendix B. Uncertainty Analysis}

An uncertainty analysis was performed to determine the accuracy of the energy savings. This was done following the ASHRAE Standard Guideline 14 (ASHRAE 2014). The uncertainty was calculated by following Equation 2:

$$
U=\frac{t}{F} \sqrt{\frac{C V(S T D)^{2}}{m}+U_{s}^{2}+R E_{\text {Instrument }}^{2}}
$$

- $\quad t$ is the $t$-statistic based on the number of samples and confidence interval.

- $\mathrm{F}$ is the approximate percentage of the baseline energy use that is saved.

- $\mathrm{m}$ is the number of periods of the savings.

- $\mathrm{CV}(\mathrm{STD})$ is the coefficient of variation of the standard deviation (as defined in the ASHRAE Guideline).

- $U_{S}$ is the uncertainty created by sampling.

- $R E_{\text {Instrument }}$ is the relative error in an instrument's measurement of a value.

The values used for Equation 2 are shown in Table 19.

- $\mathrm{t}$ is the $\mathrm{t}$-statistic for a $95 \%$ confidence interval.

- $\mathrm{F}$ is the actual energy savings from the results.

- $\mathrm{CV}(\mathrm{STD})$ was determined by following the error propagation formulas defined by the National Institute of Standards and Technology (NIST) (NIST 2017).

- The sampling uncertainty was zero for all experiments, because annual data were used to estimate the annual energy consumption.

- Finally, the uncertainty because of instrumentation was also calculated as discussed further in the following section.

The standard deviation of the legacy and EEM energy had to be found to determine CV(STD). This was done by calculating the legacy and EEM energy with a random sample of 100 permutations with various models capturing the variance. The standard deviation for legacy and EEM energy was used to calculate the energy savings error for each scenario, as shown in Table 19.

Table 19. Variables for Determining the Uncertainty of the Annual Energy Savings

\begin{tabular}{l|l|l|l|l|l|l|l|l}
\hline Variable & \multicolumn{2}{|l|}{ Scenario 1 } & \multicolumn{2}{l|}{ Scenario 2 } & \multicolumn{2}{l|}{ Scenario 3 } & \multicolumn{2}{l}{ Scenario 4 } \\
\hline Rack & A & B & A & B & A & B & A & B \\
\hline $\mathrm{t}$ & 1.96 & 1.96 & 1.96 & 1.96 & 1.96 & 1.96 & 1.96 & 1.96 \\
$\mathrm{~F}$ & 0.32 & 0.27 & 0.32 & 0.34 & 0.32 & 0.27 & 0.73 & 0.71 \\
$\mathrm{~m}$ & 1 year & 1 year & 1 year & 1 year & 1 year & 1 year & 1 year & 1 year \\
$\mathrm{CV}(\mathrm{STD})$ & 0.008 & 0.013 & 0.003 & 0.006 & 0.008 & 0.013 & 0.003 & 0.005 \\
$\mathrm{U}_{\mathrm{s}}$ & 0 & 0 & 0 & 0 & 0 & 0 & 0 & 0 \\
$\mathrm{RE}$ & $2 \%$ & $2 \%$ & $1 \%$ & $10 \%$ & $2 \%$ & $2 \%$ & $2 \%$ & $5 \%$ \\
\hline
\end{tabular}




\section{B.1 Estimating Instrument Relative Error}

Many individual measurements were required to predict energy savings. ASHRAE Guideline 14 also provided a method to estimate uncertainty because of individual measurement errors, as shown in Equation 3.

$$
R E_{\text {Instrument }}=\frac{\sqrt{\sum_{i}^{c}\left(R E_{\text {Instrument }[i]} r\right)^{2}}}{\sum_{i}^{c} \bar{r}}
$$

$\mathrm{r}$ is the value at which the error was predicted. The values used to predict $R E_{\text {Instrument }}$ are shown in Table 20.

Table 20. Variables Used to Predict Instrument Error

\begin{tabular}{l|l|l|l|l}
\hline Instrument & r & \multicolumn{2}{l}{$\boldsymbol{R E}_{\text {Instrument }[i]}$} \\
\hline Rack & A & B & A & B \\
\hline Legacy condenser power & \multicolumn{2}{l}{ Maximum condenser power } & $0.2 \%$ \\
EEM condenser power & \multicolumn{2}{l}{ Maximum condenser power } & $0.5 \%$ \\
Motor speed & \multicolumn{2}{l}{ Average motor speed } & $0.18 \% \quad 15 \%$ \\
\hline
\end{tabular}

The motor speed instrument measurement was small enough as to be negligible. However, the error as a result of using a single rpm measurement to estimate an entire circuit of motors was not negligible. To estimate the error for motor speed, the standard deviation was determined for each time step between all HRSRMs with the validation data set, because this was the only data set with HRSR motor speed measurements.

Table 21 documents the average standard deviation during the validation test period. Because multiple legacy motor speeds were never measured for a single circuit, the same standard deviation from the HRSRMs had to be used for the legacy motors. Motor speed error was also only used with VHPC, because CFSC had a constant motor speed and, therefore, insignificant measurement error.

Table 21. Motor Speed Measurement Error

\begin{tabular}{llll}
\hline Rack & $\overline{\boldsymbol{\sigma}}_{\text {Motor }}$ & $\begin{array}{l}\text { Average Motor } \\
\text { Speed }\end{array}$ & $\boldsymbol{R} \boldsymbol{E}_{\text {motor }}$ \\
\hline A & $1 \mathrm{rpm}$ & $551 \mathrm{rpm}$ & $0.18 \%$ \\
B & $69 \mathrm{rpm}$ & $464 \mathrm{rpm}$ & $15 \%$ \\
\hline
\end{tabular}




\section{References}

ASHRAE. 2014. ASHRAE Guideline 14-2014: Measurement of Energy, Demand, and Water Savings. Atlanta: ASHRAE.

Line Central International. 2017. e-motor Pro. https://www.emotorpro.com/Marathon_Refrigeration_Fan_Motors.aspx.

NIST, SEMANTECH. 2017. e-Handbook of Statistical Methods. May 14. https://www.itl.nist.gov/div898/handbook/pri/section3/pri3361.htm.

U.S. Energy Information Administration. 2012. Commercial Buildings Energy Consumption Survey. https://www.eia.gov/consumption/commercial/data/2012. 